\title{
San Jerónimo en la onomástica de la familia Martí de Torres- Aguilar y su proyección en el retablo cuatrocentista de San Martín, del Museo de Bellas Artes de Valencia
}

\section{Saint Jerome in the onomastics of family Martí de Torres-Aguilar and its reflection on Saint Martin's 15th-century reredos, displayed in the Museum of Fine Arts of Valencia}

\author{
Agustín Rubio Vela \\ rubiovela@yahoo.es
}

I. $S$.

Resumen: El estudio de la onomástica familiar de los Martí de Torres-Aguilar, comitentes del retablo cuatrocentista de San Martín, santa Úrsula y san Antonio abad, obra señera del gótico valenciano, y el análisis iconográfico de sus tablas principales, obligan a poner en duda la identificación tradicional de san Antonio abad como el representado en ellas. Tanto la onomástica como la tradición iconográfica apuntan a que la figura en cuestión corresponde a san Jerónimo.

Palabras clave: siglo XV, Valencia, San Jerónimo, Martí de Torres, Aguilar

\begin{abstract}
We have studied the family onomastics of the Martí de Torres-Aguilar, who commissioned the 15th-century raredos St Martin, St Ursula and St Anthony Abbot, a prominent piece of the Valencian gothic. This study, and the iconographic analysis of its main panels, beg the question whether the represented saint can actually be St Anthony Abbot. Both the onomastics and the iconographic tradition suggest that this figure should be matched to St Jerome.
\end{abstract}

Keywords: 15th century, Valencia, St Jerome, Martí de Torres, Aguilar

\footnotetext{
* Este trabajo se inscribe en el proyecto del MICINN (Ministerio de Ciencia, Innovación y Universidades) «La cultura literaria medieval y moderna en la tradición manuscrita e impresa (VI)», Ref. FFI2017-83960-P (AEI/FEDER, UE). Agradecemos la lectura y observaciones hechas por Josep-Enric Rubio Albarracín, Mateu Rodrigo Lizondo, Javier Sánchez Real y Juan Martínez Vinat, amigos todos, que han contribuido a mejorar el texto.
}

DATA PRESENTACIÓ: 14/10/2020 ACCEPTACIÓ: 04/11/2020 • PUBLICACIÓ: 10/12/2020 
Agustín Rubio Vela. San Jerónimo en la onomástica de la familia Martí de Torres-Aguilar y su proyección en el retablo cuatrocentista de San Martín, del Museo de Bellas Artes de Valencia

El bello retablo llamado de San Martín, santa Úrsula y san Antonio abad es una de las magníficas piezas góticas del extraordinario conjunto pictórico que, para admiración del visitante, se exhibe en el Museo de Bellas Artes de Valencia. Por ello es bien explicable que figure en lugar preferente en todos los catálogos de la entidad y que los historiadores del arte le hayan dedicado desde antiguo gran atención. ${ }^{1}$ Gracias a lo cual hoy se puede conocer con bastante precisión su procedencia -la cartuja de Portaceli-, su vinculación el linaje valenciano Martí de Torres-Aguilar, la autoría del pintor Gonçal Peris Sarrià, activo entre 1380 y 1451 y conocido hasta su identificación como «maestro de Martí de Torres», y la fecha aproximada de su ejecución, situable entre los años 1437 y 1443 (Aliaga Morell 2016: 35, 38, 43 y 50; Gómez Frechina y Ruiz i Quesada 2014: 2-3 y 37). En cuanto a la iconografía de las tres tablas principales que lo constituyen y le dan nombre (fig. 1), resulta evidente su relación con la onomástica familiar de los comitentes en dos de ellas: la central, dedicada a san Martín, y la de la izquierda, en la que se representó a santa Úrsula, que remiten, respectivamente, al apellido de Berenguer Martí de Torres y al nombre de pila de su esposa, Úrsula de Aguilar. No puede decirse lo mismo, en cambio, de la tabla de la derecha, puesto que, entre los miembros del linaje -ascendientes y descendientes-, ninguno, según veremos, era portador del nombre del santo que, según todos los autores, está representado en ella: san Antonio abad. Un dato que ha de llamar la atención del estudioso.

Pero no es el único. En la imagen que se nos ofrece en esa tabla, descrita «como un venerable anciano con gran barba blanca, adquiriendo un aspecto grave y solemne que lo reviste de monumentalidad», hay otro aspecto llamativo, digno de destacar: no responde a la iconografía antoniana convencional. Están ausentes los atributos clásicos que permiten la identificación de san Antonio de manera inequívoca: la tau, la campanilla, el fuego y el cerdo (Ollaquindia Aguirre 2004: 160). A la ausencia de estos símbolos habituales hay que añadir dos presencias: la de un libro en una mano y la de un rollo en la otra: «San Antonio Abad viste hábito talar y capucha, portando en sus manos un bordón, a modo de báculo abacial, un libro y un rollo» (Gómez Frechina y Ruiz i Quesada 2014: 41). Si el libro puede considerarse atributo conforme a la tradición iconográfica del santo abad, la presencia conjunta de un libro y de un rollo, insólita, carece de justificación.

Estas extrañas ausencias y presencias, sumadas a la inexistencia del nombre Antoni en la onomástica familiar de los comitentes, obligan a poner en duda que sea correcta la identificación del santo cotitular del retablo aceptada hasta hoy. A nuestro juicio, hay motivos tanto documentales como iconográficos para cuestionarla. En la nota que aquí comienza, exponemos, para someterlas al juicio de los historiadores del arte, las razones que nos han llevado a concluir que ha habido una confusión, ya lejana en el tiempo, de san Antonio con otro santo, también abad, que en el siglo XV sí estuvo muy presente en la onomástica y devoción de los Martí de Torres y Aguilar: san Jerónimo.

1 Para la extensa bibliografía sobre la obra remitimos a Gómez Frechina y Ruiz i Quesada (2014: 2), a la que se añadirá el artículo de Aliaga Morell (2016).

SCRIPTA, Revista internacional de literatura i cultura medieval i moderna, núm. 16 / desembre 2020 / pp. 40-70 ISSN: 2340-4841 · doi:10.7203/SCRIPTA.16.19222 
Agustín Rubio Vela. San Jerónimo en la onomástica de la familia Martí de Torres-Aguilar y su proyección en el retablo cuatrocentista de San Martín, del Museo de Bellas Artes de Valencia

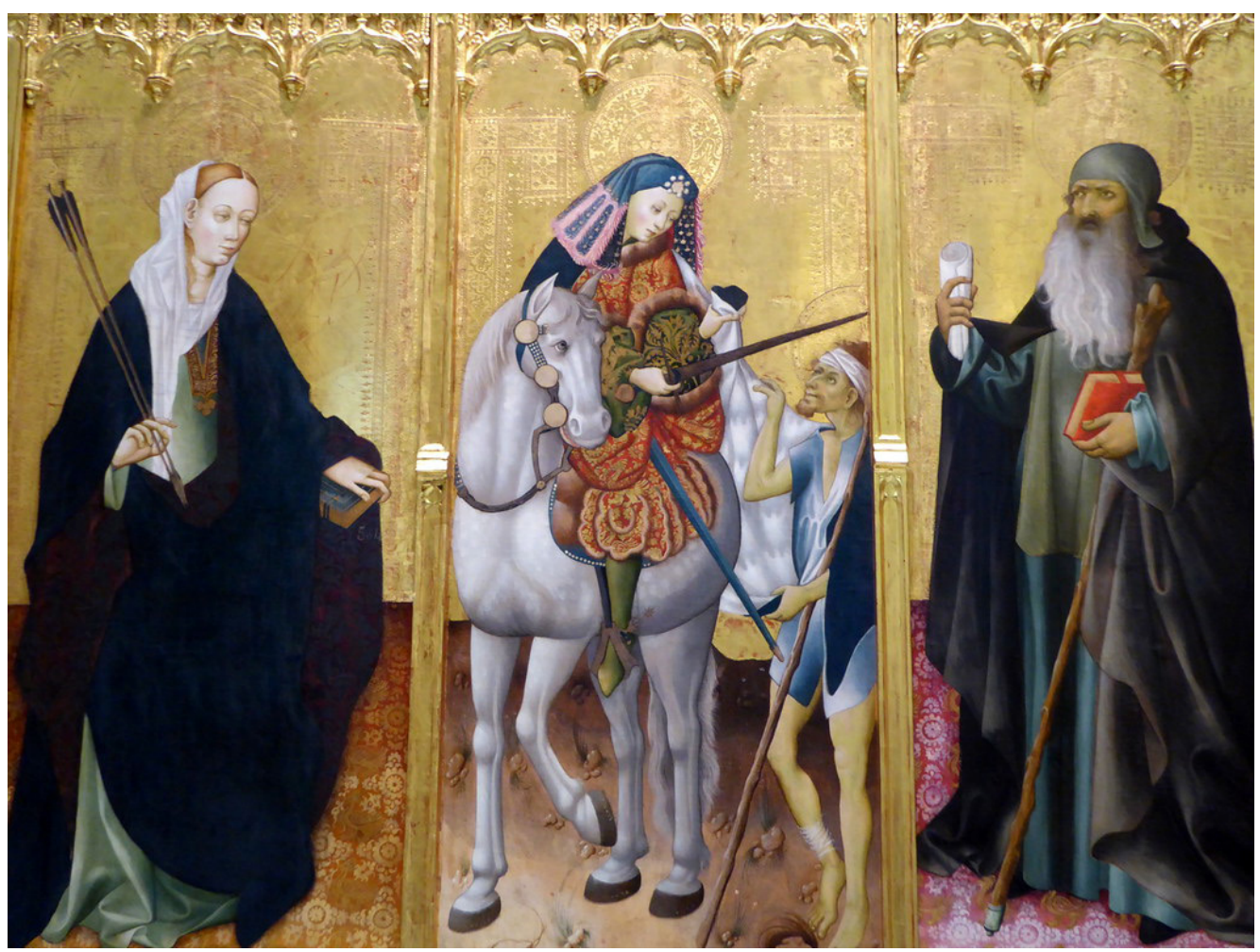

Fig. 1. Gonçal Peris Sarrià. Retablo de san Martín (cuerpo central).

Museo de Bellas Artes de Valencia.

\section{Los Martí de Torres y los Aguilar}

\section{Berenguer y Úrsula}

Existe una amplia bibliografía sobre los Martí de Torres y los Aguilar, ${ }^{2}$ dos linajes valencianos unidos a partir del matrimonio entre Berenguer Martí de Torres y Úrsula Aguilar. Se hicieron marido y mujer a mediados de la tercera década del siglo XV, cuando él ya era un importante prohombre con amplia trayectoria al servicio de la Corona y persona muy próxima a la reina María, en cuya corte permaneció entre 1421 y $1422 .^{3} \mathrm{Al}$ año siguiente volvió a Valencia, en cuyo gobierno

2 Son magníficos los trabajos de Hernàndez García (2012 y 2018) sobre la familia en general; de uno de sus miembros más notables, el jurista Jaume Garcia Aguilar, se ocupó Graullera Sanz (1998, 2007 y 2009); Rubio Vela ha estudiado aspectos de la actividad política de éste (2016), de su abuelo materno, el notario Joan Aguilar (2017), y de su hijo, Francí Aguilar (2013 y 2014); y Juan Redal (1988) ha analizado y dado a conocer las últimas voluntades de nieto homónimo.

3 De esa proximidad dan cuenta las numerosas misivas que le dirigieron los jurats de Valencia para que hiciera uso de su

SCRIPTA, Revista internacional de literatura i cultura medieval i moderna, núm. 16 / desembre 2020 / pp. 40-70 ISSN: $2340-4841 \cdot$ doi:10.7203/SCRIPTA.16.19222 
Agustín Rubio Vela. San Jerónimo en la onomástica de la familia Martí de Torres-Aguilar y su proyección en el retablo cuatrocentista de San Martín, del Museo de Bellas Artes de Valencia

ocuparía repetidamente cargos importantes. Ese mismo año fallecía en Sicilia su hermano, misser Martí de Torres -doctor en decretos, consejero del rey Alfonso el Magnánimo y obispo de Vic-, que lo nombró heredero. ${ }^{4}$ Interesa subrayar que 'Martí' fue en él apellido, mientras que en su hermano había sido nombre de pila. Probablemente lo fue también del padre de ambos, que no era, como se ha creído, el jurista valenciano Martí de Torres fallecido a finales de 1399; $;^{5}$ tal vez lo fuera un sobrino homónimo de éste, ciudadano de Xàtiva, de la casa de la noble Carroça de Vilaragut, que actuaba de testigo junto al tío, poco antes de su óbito, en un acto notarial. ${ }^{6}$ No hay constancia de que fuera éste el padre. En cualquier caso, puede afirmarse que Berenguer Martí de Torres fue el primer miembro de la familia en que 'Marti' dejó de ser nombre de pila para convertirse en apellido: un apellido compuesto, posiblemente con una finalidad ennoblecedora.

Poco después de su retorno a Valencia tras su estancia de dos años en la corte de la reina María, el hermano y heredero del obispo Martí de Torres se casaba con Úrsula, nacida en una familia culta

influencia ante la soberana en favor de la ciudad, en las que hallamos párrafos reveladores: «per què honorable sènyer, si us plaurà, donats a la dita senyora sa letra; e, si scriure vol, hajats de fet la letra sua a fi que 1 correu per aquella no sostenga dilació en son dan» (Rubio Vela 2012: I, 289, 294-296, 324; y II, 21, 48-49 y 55).

4 La correspondencia de los ediles valencianos no deja lugar a dudas. En una misiva fechada el 28 de marzo de 1421 se refieren a «l'honorable En Berenguer Martí de Torres, germà de l'honorable mossén Martí de Torres, doctor en decrets e conseller del senyor rey»; ambos gozaban de la plena confianza de los jurats, que procuraban corresponder a los favores que ellos habían realizado por la ciudad: «...com los affers dels dits micer Martí e En Berenguer Martí aquesta ciutat e nosaltres hajam per propris e pecculiars, car, per molts beneficis e servirs per aquells a la dita ciutat prestats, aquella és tenguda procurar a aquells totes honors e comoditats...» (Archivo Municipal de Valencia [AMV], Lletres missives $[L M] 15, \mathrm{f} .73 \mathrm{r}$ ). Unos meses más tarde, Martí de Torres era nombrado obispo de Vic, lo que los ediles celebraron en carta a su hermano - «al molt honorable e molt savi En Berenguer Martí, en cort de la senyora reyna»-, con palabras halagadoras: «havem haüd plaer molt gran de la promoció de mossén de Vich, e l'hauríem major de promoció de major dignitat» (ibid., ff. 135v-136r; 1421, agosto, 27). Dos años después, cuando fallecía el prelado, su hermano era jurado de la ciudad: «Per En Berenguer Martí de Torres, jurat ensemps ab nosaltres en l'any present de aquesta ciutat, qui és hereu del reverend quondam micer Martí de Torres, bisbe de Vich, nos és estat expost que en la illa de Sicília li serien estats emparats alguns béns de la dita herència...» (AMV, LM 17, ff. 12v-13r; 1423, julio, 10); “...per En Berenguer Martí de Torres, jurat ensemps ab nosaltres en l'any present d'aquesta ciutat, frare e hereu del reverent quondam micer Martí de Torres, bisbe de Vich...” (ibid., f. 62v; 1423, noviembre, 9).

5 A finales del siglo XIV se le documenta como suegro de Galceran de Riusech, casado con su hija Clareta, y de Alfonso Suárez, marido de Andrea, otra de sus hijas. Ambos fueron nombrados albaceas en su testamento, realizado el 9 de agosto de 1399 en Valencia. No tuvo hijos varones, por lo que fue su nieto, Riusec de Torres, hijo de Galceran y de Clareta, quien heredó al jurisperito: «Galcerandus de Rivosicco, miles, dominus de Valldelou et de Cotes, habitator Valentie, nomine meo proprio et tanquam pater et legittimus administrator de Riusech de Torres, adulti, filii mei heredisque universalis venerabilis Martini de Turribus, iurisperiti, avi sui socerique mei...» (AMV, Protocols, Bartomen de Vilalba 1l-8, s. fol.: 1383, diciembre, 31; id. Protocols, Jaume Desplà 2/16, f. 8r-v: 1400, enero, 24; 32v; 1400, mayo, 11; y 41 r: 1400, junio, 25; id., ibid. n-11, s. fol.: 1400, mayo, 30).

6 «Testes, Martinus de Turribus et Martinus de Turribus, nepotus eius, de domo nobilis Carrocie de Villariacuto, ac Iacobus Magranerii, notarius, vicinus de Biar»; «Nos, Carrocia de Villariaccuto, domina baroniarum de Albayda et de Corbaria, Galcerandus de Rivosicco alias Ferdinandus Eximénez de Cueva, et Clareta eius uxor, ac Martinus de Turribus, civis Xative, de domo dicte nobilis...» (AMV, Protocols, Jaume Desplà 2/15, ff. 33r-34v; 1399, marzo, 8).

SCRIPTA, Revista internacional de literatura i cultura medieval i moderna, núm. 16 / desembre 2020 / pp. 40-70 ISSN: 2340-4841 · doi:10.7203/SCRIPTA.16.19222 
Agustín Rubio Vela. San Jerónimo en la onomástica de la familia Martí de Torres-Aguilar y su proyección en el retablo cuatrocentista de San Martín, del Museo de Bellas Artes de Valencia

y acaudalada. Maciana, su madre, era hija de Guerau de Cotlliure, influyente prohombre de Llíria. Su padre, el notario Joan Aguilar, era hijo de Gonçal Aguilar, rico propietario de tierras de la Pobla de Benaguasil -hoy la Pobla de Vallbona-, que en 1371 estableció su domicilio en Valencia; Joan heredó la importante hacienda que su progenitor poseía en la citada población, así como los bienes de un tío homónimo. La exquisitez de las cartas que redactó para el gobierno municipal de Valencia en su condición de escrivà de la Sala, dan buena cuenta de la refinada cultura de Joan Aguilar (Rubio Vela 2017: 21-25), que murió en 1437, una década antes que Maciana. ${ }^{7}$ Tres años más tarde, en 1440 la viuda encargaba al pintor Garcia Sarrià un retablo para su capilla en la iglesia del convento de Predicadores (Gómez-Ferrer 2010: 43 y 44; Montero Tortajada 2013: 402).

Los bienes de Joan y Maciana pasaron a sus dos hijas, una de las cuales era nuestra Úrsula Aguilar. Cuando casó con Berenguer Martí de Torres era viuda. Había contraído matrimonio con un jurista, misser Jaume Garcia, que falleció en 1420. Cuatro años después, en marzo de 1424, Berenguer figura ya como su marido. ${ }^{8}$ Vivieron en Valencia, en la parroquia de la Santa Creu, ${ }^{9}$ en una mansión ubicada en una plaza citada en 1437 por el nombre del prócer: «la plaça d'en Berenguer Martí de Torres». ${ }^{10}$ Las menciones a esa casa, hito en los itinerarios procesionales del Cuatrocientos, son indicativas de la celebridad tanto del edificio como de la familia que moraba en él: «...entrarà en lo dit monestir de la dita nostra dona Sancta Maria del Carme, e aquí, donada devota laor de glòria a nostre senyor Déu e a la dita gloriosa Verge, nostra dona sancta Maria, e invocant lo seu beneÿt auxili, exint del dit monestir passarà davant casa de l'honorable En Berenguer Martí de Torres e entrarà en la sglésia de Sancta Creu....». ${ }^{11}$

La fortuna de Úrsula experimentaría un incremento al morir su hermana Isabel, con la que había compartido bienes procedentes de las herencias paterna y materna. Sabemos que Isabel casó en

7 El documento núm. 2 que publicamos en el apéndice aporta noticia del dato cronológico, que ya había dado a conocer Hernández García (2012: 19), y de otros de interés sobre la familia.

8 «...vobis honorabili dompne Ursole, uxori quondam prime honorabilis Iacobi Garsie, in legibus licenciati, civis dicte civitatis, nunc vero uxor honorabilis Berengarii Martini de Turribus, civis eiusdem civitatis, tanquam tutrici et curatrici Iacobi et Ioane, domicelle, pupillorum, filiorum et heredum dicti quondam honorabilis Iacobi Garsie...» (AMV, Protocols, Joan Martínez o-2, s. fol.: 1424, marzo, 24). También, doc. núm. 1 del apéndice.

9 «...lo seu alberch, lo qual té e posseeix en la parròquia de Sancta Creu, davant l'alberch del dit honorable En Berenguer Martí...» (AMV, MC 34, f. 281v; 1450, abril, 11).

10 Hernàndez García 2012: 27 y 51. En 1440, el gobierno municipal, a solicitud de Berenguer, permitía «reblir lo pou qui és en la plaçeta davant casa sua, com algú no se’n servís, e la dita plaça se n’embelliria» (AMV, MC 32, f.188v; 1440, julio, 18).

11 AMV, MC 33, f. 16r; 1444, julio, 9). Siguió siendo la vivienda de sus descendientes. Su hijo homónimo sigue figurando en los itinerarios de las procesiones de finales de la centuria: «...e girarà a man dreta e entrarà en lo monestir de la Verge Maria del Carme, e aquí axi mateix, fetes les pregàries dessusdites, exirà la dita processó e tirarà la via de casa d'En Berenguer Martí, e per la carniceria de Roteros voltarà a man dreta per lo carrer dels Serrans e tirarà per la plaça de Sent Berthomeu, e per les Corts se'n tornarà per lo portal dels Apòstols en la dita Seu» (id., MC 45, ff. 388v-389v; 1490, abril, 30); «...e de allí a la plaça de l'Alber, e per lo carreró entrarà en la Verge Maria del Carme, e axí mateix, fetes les pregàries dessús dites, exirà per casa d'En Berenguer Martí a Sancta Creu, e aquí axí mateix, fetes les dessús dites pregàries irà per casa del síndich e tornarà a la plaça de l'Alber...» (ibid., f. 391r-v; 1490, mayo, 18).

SCRIPTA, Revista internacional de literatura i cultura medieval i moderna, núm. 16 / desembre 2020 / pp. 40-70 ISSN: 2340-4841 · doi:10.7203/SCRIPTA.16.19222 
Agustín Rubio Vela. San Jerónimo en la onomástica de la familia Martí de Torres-Aguilar y su proyección en el retablo cuatrocentista de San Martín, del Museo de Bellas Artes de Valencia

primeras nupcias en 1434 con Galceran de Castellví, fallecido hacia 1446, y en segundas con el noble Pere Ramon de Montcada (Rubio Vela: 2017: 21-25; y 2020: 95 y 97-98), y que pocos años después murió sin haber hecho testamento, por lo que sus considerables riquezas -significativamente se le apodaba «la Viuda Dorada»- acabaron en manos de su hermana por sentencia judicial del 17 de octubre de $1452 .{ }^{12}$ Una notable fortuna que, tras el fallecimiento de Úrsula, pasaría a ser de sus dos hijos y herederos: Jaume Garcia Aguilar y Berenguer Martí de Torres iunior.

\section{Los hijos de Úrsula.}

Fruto del primer matrimonio de Úrsula fueron Joana, que hacia 1446 ingresó en el monasterio de la Trinitat de Valencia, ${ }^{13}$ y Jaume, que estudiaría leyes como el padre -en 1440 ya era jurista- e hizo una importante carrera política. En 1463, cuando la vida de su madre acababa, él ya se había convertido en un influyente prohombre que no sólo gozaba de importantes cargos municipales -abogado de la ciudad-, sino del favor del monarca, Juan II de Aragón, que lo nombró asesor de la batlia general del reino, consejero real, maestre racional y vicecanciller (Graullera Sanz 1998: 12-13, y 2009: 217-219; Hernàndez García 2012: 22; Rubio Vela 2016: 43). A la brillante carrera de misser Jaume pudo contribuir su vínculo familiar con el poderoso racional Guillem Çaera, hombre de máxima confianza del rey, ${ }^{14}$ que era su cuñado: Jaume casó con Violant Çaera, hermana de aquél. ${ }^{15}$

Es interesante observar que, a lo largo del tiempo, Jaume fue introduciendo cambios en su apellido. En los años cuarenta del siglo XV, cuando surgen las primeras alusiones a él en las actas municipales, siempre se le nombra por el materno: Jaume Aguilar. ${ }^{16}$ Sin embargo, más avanzada la década, entre 1447 y 1460 es citado de manera sistemática como Jacme Garcia, con el cognomen del padre, si bien,

12 «Ceterum autem dicta Ysabel obivit sine testamento et successit ab intestato prefata Ursola, soror sua et uxor Berengarii Martí de Torres, iure successionis abintestato» (AMV, Protocols, Jaume Ximeno 8-13, ff. 43r-44r).

13 «...paguí a la honorable dona Na Johana Aguilar, alias Garcia, filla de l'honorable micer Jacme Garcia, doctor en leys, quondam ciutadà de la dita ciutat [...] E jassia la dita Na Johana pochs dies ha sia entrada e religió en lo monestir de la Sancta Trinitat, construït fora ls murs de la dita ciutat...» (AMV, Claveria Censal [CCe] N-22, f. 264r-v; 1446, febrero, 21); «...als honorables micer Jacme Aguilar, doctor en leys, e Na Johana Garcia, germans, la qual Johana és monja del monastir de la Sancta Trinitat...» (ibid., f. 444v; 1446, mayo, 25). Años más tarde, Jaume era procurador de la comunidad religiosa: «Et Iacobus Garsie Aguilar, legum doctor, sindicus, yconomus et procurator reverendarum et religiosarum abbatisse et monialium conventus sancte Trinitatis extra menia dicte civitatis constructi...» (id., Protocols, Jaume Beneyto r-18, s. fol.; 1461, septiembre, 2).

14 Véase el elocuente y contundente mensaje enviado por Juan II a los jurats de Valencia en junio de 1460 (Rubio Vela 2016: 26).

15 Prueba de esa relación, hasta ahora imprecisa, es el siguiente texto: «Ego, Francescha, uxor quondam honorabilis Guillermi Çaera, legum doctoris, habitatoris Valentie, tutrix et curatrix testamentaria persone et bonorum Guillermi, Iohannis, Thome et Martini Çaera, ac Yolandis, filiorum et heredum venerabilis Francisci Çaera, quondam, civis dicte civitatis, filii communis mei et dicto viro meo ut constat de huiusmodi herentia, tutela et cura iamdictis per ultimum testamentum...» (AMV, Protocols, Jaume Beneyto r-7, s. fol.; 1443, octubre, 22).

16 En 1440 se consigna su nombre como «En Jacme Aguilar» (AMV, MC 32, ff. 206v-207r); entre 1444 y 1446 será «micer Jacme Aguilar» (id., MC 33, ff. 5v, 104r, 213r, 229r); también en 1448 (id., MC 34, f. 152r; 1448, diciembre, 23).

SCRIPTA, Revista internacional de literatura i cultura medieval i moderna, núm. 16 / desembre 2020 / pp. 40-70 ISSN: 2340-4841 · doi:10.7203/SCRIPTA.16.19222 
Agustín Rubio Vela. San Jerónimo en la onomástica de la familia Martí de Torres-Aguilar y su proyección en el retablo cuatrocentista de San Martín, del Museo de Bellas Artes de Valencia

de manera ocasional, pero anticipando la fusión que tendrá lugar más adelante, reaparece el Aguilar con la fórmula Garcia alias Aguilar: «micer Jacme Garcia alias Aguilan»; «Iacobus Garcia alias Aguilar, legum docton». ${ }^{17}$ El 2 de enero de 1460, los jurats se dirigen a él como «micer Jacme Garcia Aguilan». ${ }^{18}$ En adelante, en las actas municipales lo encontraremos casi siempre citado de este modo, con los apellidos paterno y materno, aunque a veces se suprime el segundo. El giro onomástico se había consolidado, aunque aún faltaba un último cambio -leve, pero significativo-, que advertimos a partir del 10 de mayo de 1465: la incorporación de la ornamental preposición 'de' entre los dos apellidos. ${ }^{19}$ Hasta el final de sus días, el hijo de mayor de Úrsula Aguilar ya será misser Jaume Garcia d’Aguilar.

Hay indicios, no obstante, de que siempre se le llamó Jaume Aguilar, la denominación que se le daba en los textos más antiguos. El racional Çaera, su cuñado, en una misiva dirigida a los jurats fechada el 12 de febrero de 1471, escribía: «....yo he presentada la letra de creença als magníffichs N’Arnau Constantí, jurat, e micer Jacme Aguilar...». ${ }^{20}$ Un dato que apunta a que en la Valencia de la época, al margen de todos los cambios que fue introduciendo a lo largo de su vida en los escritos de carácter público, las gentes lo conocían por este nombre.

Del segundo enlace matrimonial de Úrsula nació un varón que fue bautizado con el nombre de su padre, Berenguer Martí de Torres. La homonimia obligaría a diferenciarlo en la documentación, que, a partir de 1448, lo presenta como Berenguer Martí de Torres, menor de dies, o pus jove. ${ }^{21}$ Él mismo tenía que aludir a su padre, precisando que lo era, como Berenguer Martí de Torres, maior. «ego, Berengarius Martí de Torres, civis civitatis Valentie [...], honorabili Ursole, uxori honorabilis Berengarii Martí de Torres, civi dicte civitatis, natu maiori, genitori meo». ${ }^{22}$ Así fue hasta que en 1466 éste falleció, por lo que en adelante sólo se mencionará a un Berenguer Martí que, obviamente, era él. ${ }^{23}$

Tres años antes, Úrsula, madre de éste y esposa de aquél, dejaba de existir, y Berenguer Martí de Torres y su hermano, Jaume Garcia Aguilar partían la herencia tras ser declarados herederos por

17 AMV, MC 33, f. 30r (1444, septiembre, 10); (id., Protocols, Joan de Santfeliu q-8, s. fol.; 1445, julio, 1); id., CCe I-65, f. 18r (1448, agosto, 30). «De micer Jacme Garcia [...] vobis eidem Iacobo Garcie alias Aguilar, legum doctori, civi dicte civitatis...» (id., Protocols, Jaume Beneyto r-16, s. fol.; 1458, agosto, 14).

18 AMV, LM 23, f. 258v.

19 AMV, MC 37, f. 214r-v (segunda foliación).

20 AMV, MC 38, f. 180r-v (segunda foliación).

21 «...de l'honorable En Berenguer Martí, pus jove...» (AMV, MC 34, f. 72r; 1448, abril, 16); «...lo honorable En Berenguer Martí, menor de dies, fill del dit En Berenguer Martí, ciutadà...» (id. MC 36, f. $121 \mathrm{r}-\mathrm{v}$ [segunda foliación]; 1458, octubre, 2); «...En Berenguer Martí, menor» (id. MC 38, f. 5r; 1465, junio, 8).

22 AMV, Protocols, Jaume Ximeno 8-13, ff. 43r-44r (1481, abril, 12).

23 La referencia al año de su muerte la da el Llibre de Benefactors de Portaceli, donde se indica que allí «edificá la Capella de Sant Martí» en una fecha que se desconoce: «ignoras quin any» (Tarín Juaneda 1897: 275-276).

SCRIPTA, Revista internacional de literatura i cultura medieval i moderna, núm. 16 / desembre 2020 / pp. 40-70 ISSN: 2340-4841 · doi:10.7203/SCRIPTA.16.19222 
Agustín Rubio Vela. San Jerónimo en la onomástica de la familia Martí de Torres-Aguilar y su proyección en el retablo cuatrocentista de San Martín, del Museo de Bellas Artes de Valencia

sentencia del justícia civil, ya que aquélla había muerto sin haber hecho testamento: «predicta Ursola obivit ab intestato et successerunt eidem magniffici Iacobus Garcia de Aguilar et Berengarius Martí de Torres, eius filii»». ${ }^{24}$

\section{Los hijos de misser Jaume Garcia Aguilar.}

Jaume Garcia Aguilar y Violant Çaera tuvieron dos hijos varones: Miquel y Francesc Aguilar. El primero, que, como primogénito recibiría del padre en 1469 - en vida de éste- el señorío de Alaquàs, comprado a los Vilaragut (Hernàndez García 2012: 20 y 23; y 2015: 12), es menos conocido que el menor, por una razón de índole literaria: éste falleció en 1482 en Córdoba, durante la guerra de Granada, «en lo verd de la florida joventut», y Joan Roís de Corella le dedicó una bella composición fúnebre titulada «Sepultura de Francí Aguilar», en la que exaltó «los actes e virtuosa vida d'aquell estrenu cavaller [...], el qual pocs dies havia que, en la ciutat de Còrdova, de la gran Espanya, ab fi cristianíssima, d'aquesta miserable vall de làgrimes era passat en eterna glòria" (Rubio Vela 2013: 611-613; y 2014: 450-456 y 461-462).

Aunque ignoramos cuándo vieron la luz los dos hijos varones del jurista, parece verosímil situar sus nacimientos por el tiempo en que Berenguer Martí de Torres, padrastro de su padre, encargaba el retablo para la capilla que fundó en Portaceli. ${ }^{25}$ Lo que sí nos consta es que con ellos se inauguró una tradición familiar que había de tener largo recorrido: al bautizarlos, tras el nombre de pila, se quiso que ambos, tanto Miquel como Francesc, llevaran como segundo nombre el de Jerónimo. Algo sin precedentes en el linaje, y que a todas luces hay que atribuir a una particular devoción de misser Jaume Garcia Aguilar por el santo,

El dato onomástico es bien conocido en el caso del primogénito, que figura como Miquel-Jeroni en la documentación coetánea. En 1471, cuando ya había sido elevado al rango de caballero -del que carecían sus antepasados paternos y maternos, todos ellos de condición ciudadana-, era citado así: «Michael Ieronim Garcia d'Aguilar, miles, habitator Valentie». ${ }^{26}$ En los llibres de claveria censal de 149394 se registran pagos «al magnífich mossén Miquel Jerònim Garcia d'Aguilar, cavaller». ${ }^{27}$ En 1485 fue uno de los prohombres que redactaron en la Sala del consell de la ciudad unas ordenanzas «sobre

\footnotetext{
24 «...successerunt eidem Ursole magnifficus Iacobus Garcia de Aguilar, legum doctor, et ego, dictus Berengerius Martí, fratres et filii dicte Ursole, equis portionibus [...]; ego, dictus Berengarius Martí, cum magniffico Iacobo Garcia, fratre meo, venimus...» (AMV, Protocols, Jaume Ximeno t-14; 1482, junio, 22).

25 Francí, el menor, podría tener entre quince y veinte años en 1466, cuando recibió el cargo honorífico de trinxant del príncipe Fernando (Vicens Vives 2006: 617).

26 AMV, Protocols, Bernat Santfeliu 13-21, s. fol. (1471, febrero, 22); ibid. 14-2, f. 272v (1471, julio, 13).

27 AMV, CCe I-110, ff. 14r, 45v y 182v.
}

SCRIPTA, Revista internacional de literatura i cultura medieval i moderna, núm. 16 / desembre 2020 / pp. 40-70 ISSN: 2340-4841 · doi:10.7203/SCRIPTA.16.19222 
Agustín Rubio Vela. San Jerónimo en la onomástica de la familia Martí de Torres-Aguilar y su proyección en el retablo cuatrocentista de San Martín, del Museo de Bellas Artes de Valencia

la prohibició de no entrar vi fora contribució»; allí se le cita como «mossén Jerònim Aguilar». ${ }^{28}$ No es la única vez. Un año antes, en la lectura del testamento de su padre, el notario, tras referirse a él como «Miquel Geronim Aguilar», escribió: «E axí mateix los dits mossen Geronim e la dita Catherina d'Aguilar...» (Graullera Sanz 1998: 16). También en 1487, «Hieroni García de Aguilar y su hermana Yolanda hacían mención a ciertos censales cargados por su padre el Jurista Jaume García», según Graullera (2009: 219). Lo que parece apuntar a que se le conocía más por su segundo nombre de pila que por el primero, sobre todo si se tiene en cuenta la reiteración de las citas documentales al respecto: en 1471 se le menciona como «Jerònim Aguilar, fill de micer Jaume Aguilar e genre de mossén Vidal de Blanes» (Hernàndez García 2012: 22); y en 1498, cuando fue elegido uno de los seis consellers cavallers de ese año, aparece como «mossén Jerònim Aguilar». ${ }^{29}$ No menos significativo resulta el hecho de que en un mismo protocolo notarial se le cite en 1496 como «Miquael Ieronimus Garcia d'Aguilar, miles», y al año siguiente como «Ieronimus Garcia de Aguilar miles». ${ }^{30}$

Pero también Francí, al igual que su hermano mayor, era portador del nombre del santo. Ciertamente, en la mayor parte de las ocasiones sólo figura con el primero de sus nombres, como en la composición corelliana (Rubio Vela 2014: 461), o como en 1484, cuando el notario se refería a «la magnifica na Catherina d'Aguilar, viuda, muller del magnifich en Franci d'Aguilar, quondam, ciutada» (Graullera Sanz 1998: 16). Pese a lo cual, no hay duda de que su nombre completo era Francesc-Jeroni. Lo demuestra su nombramiento en 1481 como conseller de la ciudad: en la misma página del libro de actas en que aparece «mossén Miquel Jerònim Garcia de Aguilar», su hermano, elegido conseller por los «cavallers e generosos», figura él, designado conseller ciutadà por la parroquia de Santa Maria, en estos términos: «En Francesch Jerònim Garcia de Aguilan» (Rubio Vela 2014: 461). Más contundente aún es el privilegio de Juan II, expedido en Barcelona en 1478, por el que le concedía la gracia de compartir con su padre el cargo de maestre racional; en el registro de cancillería, tras la indicación «Hieronimi Garcie d'Aguilar, filii magnifici Iacobi Garcie, legum doctoris», el documento comienza así: «Nos, Ioannes, etc. Conçessimus nuper magnifico dilecto consiliario et vicecancellario nostro Iacobo Garcie d'Aguilar, legum doctori, patri vestri, magnifici et dilecti nostri Francisci Hieronimi Garcie d'Aguilar, officium magistri rationalis curie nostre in predicto regno Valentie sicuti in provisione nostra, ad quam nos refferimus, continetur». ${ }^{31}$

Así pues, fue voluntad manifiesta del jurista Jaume Garcia Aguilar que su fervor por san Jerónimo quedara reflejado en la onomástica de sus dos hijos varones. Algunos de sus nietos y biznietos también llevaron ese nombre.

28 AMV, MC 44, f. 184r (1485, octubre, 26).

29 AMV, MC 49, f. 206v (1498, junio, 3).

30 AMV, Protocols, Pere Gisquerol 15-2, s. fol. (1496, agosto, 12; y 1497, febrero, 3).

31 Archivo del Reino de Valencia, Real Cancillería 294, ff. 178v-179r (1478, abril, 28). Dan cuenta de esta concesión Cruselles (1989: 108 y 146) y Graullera Sanz (1998: 13). El primero incurre en doble error al afirmar que FrancescJeroni era «doncel y escribano real».

SCRIPTA, Revista internacional de literatura i cultura medieval i moderna, núm. 16 / desembre 2020 / pp. 40-70 ISSN: $2340-4841 \cdot$ doi:10.7203/SCRIPTA.16.19222 
Agustín Rubio Vela. San Jerónimo en la onomástica de la familia Martí de Torres-Aguilar y su proyección en el retablo cuatrocentista de San Martín, del Museo de Bellas Artes de Valencia

\section{La descendencia de Francí Aguilar.}

Francí contrajo matrimonio. Su esposa, que aparece en 1478 como «Na Caterina Amalrich, muller d'En Francesch Garcia de Aguilans, ${ }^{32}$ le dio varios hijos, que quedaron huérfanos al morir aquél, inesperadamente, en las lejanas tierras andaluzas. El mayor de ellos ostentó el nombre y apellidos de su abuelo, que sobrevivió dos años a su padre: él es el Jaume Garcia Aguilar que aflora en documentos valencianos de finales de la centuria, cuando misser Jaume había fallecido. ${ }^{33}$ A él iría a parar la herencia de su tío, Berenguer Martí de Torres, que estaba destinada a su padre, Francí, según se desprende de las palabras de Joan Roís de Corella referidas al dolor que la desaparición de éste provocó en su familia: «ha deixat noble senyor e pare, ensemps ab un estimat oncle lo qual, sens fill, ab sobreabundant heretat, adoptant-lo en fill, llargament l'heretava» (Gustà 1980: 41). La muerte temprana de Francí durante la guerra contra los moros granadinos explica que fuera su hijo mayor Jaume, llamado Jaumot en su juventud, ${ }^{34}$ el beneficiario de los cuantiosos bienes procedentes de sus bisabuelos, Berenguer y Úrsula.

Pero Jaume no fue el único hijo de Francí. Tuvo tres varones más, llamados Francesc, Dimas y Miquel-Jeroni (Hernàndez Garcia 2012: 23). A este último le dio por segundo nombre de pila Jeroni, convirtiendo en tradición lo que con él y su hermano había hecho su padre, misser Jaume. Parece que normalmente no era llamado Miquel-Jeroni, sino sólo Jeroni. De manera reiterada lo denomina así, en 1538, su hermano Jaume en sus últimas voluntades, cuando lo nombró albacea junto con otro hermano y su hijo: «als nobles don Hieronym de Aguilar e don Dimas de Aguilar doctor en leys germans meus e don Berenguer Marti de Torres e de Aguilar fill meu legitim e natural» (Juan Redal 1988: 29, 32, 33, 34 y 37). Así pues, el santo pervivió en la onomástica del linaje por voluntad de Francí. Pero no sólo. Pero también tuvo esa misma voluntad Jaume, su hijo mayor, como vamos a ver.

Consta que Jaume casó con Isabel, una hija legitimada de su tío Berenguer Martí de Torres, ${ }^{35}$ que hubo de adoptar el nombre y armas de su suegro y tío, por lo que en la documentación aparecerá

32 AMV, Protocols, Notals de Jaume Ximeno t-10, s. fol. (1478, agosto, 18).

33 «...Iacobus Garcia de Aguilar, et pro eo Gaspar Amalrich, civis, procurator ipsius...» (AMV, Protocols, Pere Gisquerol 15-1, f. 7r; 1495, abril, 30). El mismo día, su madre figura con los apellidos del marido: «...Caterina Garcia de Aguilar et pro ea Gaspar Amalrich, civis, ut proc. ipsius...» (ibid., f. 7v); «...Caterina Aguilar, uxor magnifici Francisci Aguillar, quondam civis, et pro ea Gaspar Amalrich, civis...» (ibid., f. 8r).

34 El 16 de febrero de 1484, en un acto notarial acerca sobre el testamento de su abuelo, actuaban su tío y su madre «en nom de tudors e curadors testamentaris de Jachmot Aguilar pubil, per virtud del testament del dit pare seu, e altre dels hereus scrit en lo dit testament del dit deffunct, avi del dit Jachmot pobil» (Graullera Sanz 1998: 16).

35 No debió de tener hijos en su matrimonio. Consta que en 1449 se casó, pues su madre le donó en esa fecha un censo en contemplación de su enlace: «...Ceterum autem predicta honorabilis Ursola, mater dicti Berengarii de Torres iunioris, fecit donationem de predicto censuali [...] contemplatione matrimoni eidem Berengario...» (AMV, Protocols Jaume Ximeno 8-13, ff. 113v-114r; 5 octubre 1481, octubre, 5). 
Agustín Rubio Vela. San Jerónimo en la onomástica de la familia Martí de Torres-Aguilar y su proyección en el retablo cuatrocentista de San Martín, del Museo de Bellas Artes de Valencia

también como Berenguer Martí de Torres i Aguilar, y que heredó la baronía de Alaquàs a la muerte de su tío Miquel-Jeroni (Hernàndez García 2012: 43, y 2015: 15-16; y Juan Redal 1988: 31). Y consta asimismo su decisión de proseguir con la tradición onomástica inaugurada por su abuelo, ya que bautizó como Caterina-Jerònima a la segunda de sus hijas, casada con Pero Aznar Pardo de la Casta, a la que, eliminando el primero de los dos nombres de pila, alude en sus voluntades testamentarias como «dona Hieronyma Aguilar filla mia legitima e natural e de legitim matrimoni nada e procreada muller del noble Don Pedro Pardo de la Casta» (Juan Redal 1988: 31).

\section{La orden jerónima en Valencia}

Establecidos en 1376 en Xàbia, en las faldas del Montgó, los jerónimos fundaron sus primeras casas en Gandia -Sant Jeroni de Cotalba (1388)-, en Alzira -Santa Maria de la Murta (h. 1401)y, mucho más tarde, en Segorbe -Nuestra señora de la Esperanza (1495)-, bien conocidas y bastante estudiadas (Delicado Martínez y Ballester Hermán 2000; Campón 1991; López-Yarto, Mateo Gómez y Ruiz Hernando 1995; Palomar Macián 2017). No lo ha sido aún su presencia en la comunidad de la Vall de Jesús, ubicada en las proximidades de Puçol, «en lo erm devers les muntanyes, dins lo terme de Morvedre», de la que hay constancia en 1413: el 24 de junio de ese año, los jurats de Valencia enviaban una misiva «al molt religiós honest lo prior dels frares del monestir de Sent Jerònim, prop Puçol», para pedirle que enviase al día siguiente a la ciudad «aquest vostre frare qui s'entén de livellar e traure aygües», del que tenían «gran necessitat e cuyta» por causa de la sequía. ${ }^{36}$ Dos años después, en mayo de 1415 , volvía a aludirse a «lo hermità del monestir de la vall de Jesús, qui [é]s prop lo loch de Puçol», como experto, para «fer venir l'aygua de Santa Cruç». ${ }^{37}$ Lo cual prueba de manera inequívoca la presencia jerónima en este establecimiento, que tuvo una vida efímera: se disolvió como consecuencia de un escándalo protagonizado por uno de sus miembros, aunque fue restaurado a mediados de la centuria como convento de franciscanos observantes. ${ }^{38}$

Desde comienzos del siglo XV hay también constancia de la actividad de frailes de la orden en la capital del reino: en 1408 se documenta en ella a «frater Alfonsus de Salamanca, procurator, yconomus prioris et conventus fratrum sancti Ieronimi», ${ }^{39}$ y en 1445 a un «frare Jacme Romeu, de l'orde de sent Jeroni" (Rubio Vela y Rodrigo Lizondo 1984: 333). En 1439, el notario Joan Marromà, padre de un jurista del

\footnotetext{
36 AMV, LM 12, f. 9v.

37 AMV, MC 26, f. 13r.

38 En 1454 y 1455, los jurats valencianos se referían a los anteriores ocupantes de aquella «casa o monestir, ab sa devota capella, appellada Vall de Jesús», como «canonges [que], a manera de hermitans, sots la regla de Sent Agostí, habitaven e visqueren devotament per alguns temps» (Teixidor 1895: I, 355-356; Rubio Vela 2000: 211-215, 218-219 y 251-253). Los jerónimos, como es sabido, se regían por la regla de san Agustín.
}

39 AMV, Protocols, Joan de Santfeliu 20-1 (1408, junio, 30 y octubre, 31)

SCRIPTA, Revista internacional de literatura i cultura medieval i moderna, núm. 16 / desembre 2020 / pp. 40-70 ISSN: 2340-4841 · doi:10.7203/SCRIPTA.16.19222 
Agustín Rubio Vela. San Jerónimo en la onomástica de la familia Martí de Torres-Aguilar y su proyección en el retablo cuatrocentista de San Martín, del Museo de Bellas Artes de Valencia

mismo nombre, dispuso en su testamento ser enterrado una pequeña iglesia dedicada al santo abad ubicada extramuros, en las proximidades del monasterio de Sant Vicent: «Yo, En Johan Marromà, notari [...] elegesch la mia sepoltura en la sglèsia de monsènyer Sanct Jerònim, qui és prop lo monestir de Sanct Vicent de la dita ciutat.. ${ }^{40}$ Junto a ella había una comunidad jerónima, a juzgar por un acta notarial, fechada en 1461, referida la casa con huerto de un ciudadano de Valencia, «situat en lo camí de Sent Vicent, fora lo portal, en una cantonada a la man dreta, anant a la sglésia e monestir del benaventurat màrtir mossènyer Sent Vicent, assats prop deçà lo monestir e esglèsia de mossènyer Sent Iherònim». ${ }^{41}$

Este establecimiento, aludido como «casa e sglésia», era una extensión del monasterio gandiense de Cotalba, como demuestra el texto de la concordia firmada en 1483 entre éste y la confraria o almoina de l'ofici de velluters creada en Valencia en 1477 bajo la advocación de san Jerónimo, para el uso de «la capella del dit gloriós Sent Gerònim, construhyda fora los murs de la present ciutat de València, prop lo monestir de Sent Vicent»; una capilla que pertenecía a la casa: «domum fratrum dicti Santi Geronymi, quam fratres eiusdem habent in civitate Valentie extra portale Santi Vincentii et muros dicta civitatis» (Navarro Espinach y Martínez Vinat 2016: 313-314, 325, 348-358).

Años antes, en 1469, un ermitaño llamado Nicolau Joan dejó en herencia a los jerónimos del otro monasterio valenciano, el de la Murta, una ermita, bajo la invocación de san Sebastián, con los campos que la circundaban, situada también fuera del circuito amurallado de la urbe; sobre ella, tras aceptar los frailes el ofrecimiento de un prohombre para erigir una iglesia a condición de tener allí su sepultura, en 1480 se comenzó a erigir un templo «sots invocació del glorios Mosenyer Sent Sebastiá ab los gloriosos Sants Hieronym e San Honofre», al que ocho años más tarde se referían los jurats como «la Ecclesia del Monestir de Sant Sebastià que novament se construix e edifica, fora los murs de la present Ciutat, la qual Ecclesia e Monestir es dels Reverents Frares de la Verge Maria de la Murta del Orde de San Jeronim» (Teixidor 1895: II, 51-52). ${ }^{42}$

En la Sepultura de Francí Aguilar, Joan Roís de Corella proporciona un dato muy interesante sobre una de estas dos presencias de jerónimos en la ciudad de Valencia. Relata Corella en ese bello texto, que escribió en 1482 tras la muerte de Francí, cómo él, al salir de la ciudad camino hacia la iglesia de Sant Vicent, donde se encontraría con la imaginaria capilla ardiente de aquél, hizo una parada en «una religiosa capella sots invocació del sant gloriós doctor Jerònim» (Gustà 1980: 33). Era una alusión, obviamente intencionada, a la pequeña iglesia dedicada al santo abad allí existente, a la que antes nos hemos referido, con la que el autor quiso evocar el fervor de los Aguilar por san Jerónimo, de cuyo nombre era portador el combatiente difunto.

40 AMV, Protocols, Joan de Santfeliu q-5, s. fol. (1439, mayo, 22).

41 AMV, Protocols, Jaume Beneyto r-17, s. fol. (1461, abril, 13).

42 Confirman esta otra casa de jerónimos en los aledaños de la capital las cartas enviadas en 1489 por los ediles a las comunidades religiosas del reino pidiendo oraciones por los ejércitos cristianos combatientes en Granada, una de las cuales fue dirigida «als molt reverents e de sancta e honesta vida e perfeta relegió los frares de l'orde de Sent Jerònim residents en lo monestir de Sent Sabastià, prop València» (AMV, LM 32, ff. 67v-69r; 1489, julio, 13).

SCRIPTA, Revista internacional de literatura i cultura medieval i moderna, núm. 16 / desembre 2020 / pp. 40-70 ISSN: $2340-4841 \cdot$ doi:10.7203/SCRIPTA.16.19222 
Agustín Rubio Vela. San Jerónimo en la onomástica de la familia Martí de Torres-Aguilar y su proyección en el retablo cuatrocentista de San Martín, del Museo de Bellas Artes de Valencia

Esa devoción a san Jerónimo de los Aguilar, iniciada por misser Jaume, padre de Francí, ha de enmarcarse en la creciente presencia de los frailes de la orden jerónima en la capital del reino. Una influyente presencia que tuvo su proyección en la onomástica masculina y femenina de la ciudad, donde, al igual que ocurrió en otras urbes en el Cuatrocientos, se popularizó el nombre del santo (Russo 1987: 137 y 176). Hecho significativo y elocuente es el contraste entre la total inexistencia de personas llamadas 'Jeroni'/'Jerònima' en las relaciones de habitantes de Valencia de mediados del siglo XIV (Rubio Vela y Rodrigo Lizondo 1997), y los más de cien individuos, entre hombres y mujeres, que así se llamaban, según el censo de 1510: 18 pertenecientes al estamento militar y 90 al ciudadano (Valldecabres Rodrigo 2002). Esta difusión del nombre constituye un dato indicativo del éxito e influencia social que consiguieron aquellos frailes de espiritualidad exigente, rigorista, próxima a la de los franciscanos observantes, con quienes, como han puesto de relieve los estudiosos de la espiritualidad jerónima, compartían el ideal de pobreza evangélica. ${ }^{43}$

Favorecidos por el patriciado de la capital, ${ }^{44}$ los jerónimos, pocas décadas después de su temprana llegada al reino, habían popularizado la figura del santo fundador de su orden. Debieron contribuir también a difundir una imagen nueva de san Jerónimo como modesto religioso, acorde con sus ideales de pobreza. Una imagen austera, ascética, distinta de la del san Jerónimo doctor, padre de la Iglesia, vestido de cardenal. El venerable abad con hábito talar del retablo del Museo de Bellas Artes parece responder a la sensibilidad religiosa que los jerónimos estaban expandiendo por tierras valencianas cuando la obra se llevó a cabo por encargo de los Martí de Torres-Aguilar.

\section{Sobre el retablo de la capilla familiar}

\section{Pintores, sabios y comitentes}

A partir de los estudios de Ferre Puerto (1999), el presbítero Andreu Garcia, beneficiado de la catedral de Valencia, es considerado por los historiadores del arte una importante figura en el panorama pictórico del siglo XV valenciano, no sólo por su relación con artistas de la época, sino por su influencia en la temática de los retablos. Según Gómez-Ferrer (2010: 42-44), «fue conocido en el campo de las artes [por] aconsejar sobre un cambio de iconografía y ofrecer una solución alternativa para la terminación de

\footnotetext{
43 «Je rappellerai les liens étroites existant entre les Spirituels et le Frères Ermites de Saint-Jerôme», ha escrito uno de los más relevantes, que insiste: «Les liens sont donc multiples entre les communautés de Hiéronymites et les Spirituels Franciscains» (Russo 1987: 117-138 y 162-163).

44 En 1484, los jurats en carta «a frare Rodrigo de Orenes, lo senyor general de l'orde de Sent Jerònim», se interesaban, encomiándolo, por «lo devot e honest religiós frare Diego de Toledo, mestre en sacra theologia, famós sermonador, lo qual molt bé e sanctament se regex e dónen gran fruyt les sues prehicacions» (AMV, LM 30, f. 302r-v; 1484, septiembre, 2). Un año antes se le instaba a que autorizara la intervención, como mediador en un enfrentamiento entre dos nobles, don Mateu de Montcada y don Joan de Gallano, de «frare Johan Batista de Vilaragut, del vostre orde», convencidos de que «tendrà alguna reverència entre aquells» (ibid., ff. 225v-226r; 1483, septiembre, 21).
}

SCRIPTA, Revista internacional de literatura i cultura medieval i moderna, núm. 16 / desembre 2020 / pp. 40-70 ISSN: 2340-4841 · doi:10.7203/SCRIPTA.16.19222 
Agustín Rubio Vela. San Jerónimo en la onomástica de la familia Martí de Torres-Aguilar y su proyección en el retablo cuatrocentista de San Martín, del Museo de Bellas Artes de Valencia

algunas de las escenas». La citada autora ha subrayado la «gran amistad» que le unió con Gonçal Sarrià, y aludido al pago que en 1439, por medio de él, recibió Joan Reixach por unas pinturas que realizó para la cartuja de Portaceli; también se ha referido a su intervención, en 1440, en un contrato entre este último y Maciana, la viuda del notario Joan Aguilar para la realización de un retablo que había encargado a Garcia Peris Sarrià y que éste no pudo ejecutar al haberle sobrevenido la muerte; en dicho contrato, el pintor «se comprometía a terminarlo con algunas diferencias iconográficas respecto a lo inicialmente pactado», siguiendo las indicaciones de Andreu Garcia.

Así pues, el criterio iconográfico de Andreu Garcia era tenido en cuenta tanto por los pintores como por los comitentes de sus obras, entre los cuales se encontraba Maciana, la madre de Úrsula Aguilar. El clérigo había de ser pariente del que fuera primer marido de ésta, misser Jaume Garcia, a juzgar por su testamento, redactado el 10 de junio de 1450 y dado a conocer por Montero Tortajada (2013: 407): de los cuatro albaceas que designó, uno era su hermano, el fraile Jaume Garcia, custodio de los franciscanos observantes del reino de Valencia, y otro el jurista misser Jaume Garcia Aguilar, el hijo de Úrsula. A lo que cabe añadir otro dato de interés: la estrecha vinculación de Andreu con la orden cartuja: ordenó que su cuerpo, vestido con el hábito de esa orden, fuese enterrado en Valldecrist, junto al de su madre.

Los saberes iconográficos de Andreu Garcia, su proximidad familiar a los Aguilar, sus relaciones amistosas con el círculo pictórico de los Peris y su amor hacia la orden de san Bruno, a la que pertenecía la cartuja de Portaceli, son datos que fundamentan la sospecha de su posible intervención en la realización y destino del retablo de san Martín. Su criterio pudo ser tenido en cuenta en la ejecución de las figuras representadas en él, dos de las cuales no ofrecen la menor duda: san Martín y santa Úrsula. Una y otra están sobradamente justificadas - «justificadísima», escribió Saralegui (1954: 88), refiriéndose a la santa- pues corresponden a la onomástica de los comitentes: Berenguer Martí de Torres y Úrsula de Aguilar. Nombre de pila en el caso de la dama, y apellido en el de aquél, si bien en su familia, como se ha visto, había sido nomen antes transformarse en cognomen. San Antonio abad, supuestamente representado en la tercera tabla, por el contrario, nada tiene que ver ni con la onomástica ni con las devociones familiares de los Martí de Torres y de los Aguilar. Y ello, dado que las figuras de las otras dos tienen una clara justificación, ha de resultar extraño. Extraño e inexplicable. ${ }^{45}$ La pregunta surge inevitablemente: ¿se trataba de san Antonio?

Cualquiera que fuese el erudito que orientara al artífice de la obra pictórica, sus instrucciones, a juzgar por el resultado, debieron de ser éstas: ha de representarse un anciano abad con barba, solideo gris, hábito religioso -túnica azul y manto negro con capucha-, bastón, portador en la mano derecha de un libro en formato de codex, y de un rollo en la izquierda. De haber querido que se identificase esa figura con san Antonio abad, es obvio que hubiera ordenado introducir alguno los atributos que hacían reconocible de manera inequívoca a éste. No lo hizo. Leandro de Saralegui (1954: 96) los echaba de menos, no sin extrañeza: «Tampoco aquí lleva el báculo abacial con (o sin) pañizuelo y tal cual vez la campanilla solicitadora de limosna. Sólo tiene un largo bordón verde y nudoso, no rematado en la $T$ del

45 «Desconocemos el porqué de la elección de San Antonio Abad, este elemento lo dejaremos en punto muerto

SCRIPTA, Revista internacional de literatura i cultura medieval i moderna, núm. 16 / desembre 2020 / pp. 40-70 ISSN: $2340-4841 \cdot$ doi:10.7203/SCRIPTA.16.19222 
Agustín Rubio Vela. San Jerónimo en la onomástica de la familia Martí de Torres-Aguilar y su proyección en el retablo cuatrocentista de San Martín, del Museo de Bellas Artes de Valencia

'thau' o Cruz egipcia de su nombre, insignia de la Orden». La razón de estas ausencias, a nuestro juicio, es que el santo abad, contrariamente a lo que creyó Saralegui, no era san Antonio, sino san Jerónimo, tan venerado por misser Jaume Garcia Aguilar, hijo de los comitentes, que llamó a sus dos varones MiquelJeroni y Francesc-Jeroni. Hay más argumentos que permiten sostener nuestra interpretación.

\section{Atributos de un santo traductor}

Los dos tipos iconográficos que predominan en las representaciones de san Jerónimo, el de cardenal y el de religioso, están presentes en el retablo de san Martín, ya que el santo está también en la predela, en menor escala, representado sedente, como padre de la Iglesia, con la púrpura cardenalicia. ${ }^{46}$ Para la tabla principal se prefirió una imagen diferente: la del San Jerónimo monje; la del monje que fundó su orden y tradujo la Biblia, tal como lo presentaban los textos hagiográficos de la época. En uno de los que circulaban en el Cuatrocientos, atribuido a su discípulo san Eusebio, éste evocaba así al santo en el monasterio que creó en Belén: «En lo qual loch [Bethleem] construí e feu monestir, e ordenà religió fort santa e streta per servir nostre senyor Déu. En lo qual monestir ell ajustà molts sants e perfets dexebles; entre'ls quals yo, Eusebi, indigne, fuy un. En lo qual monestir, segons que desús és dit en los primers capítols, ell visqué cinquanta anys e sis mesos en fort gran puritat e santedat de vida, e per bones obres e per santes doctrines instruint les gents, e trasladant e compilant e exponent les santes scriptures, axí com la Bíblia e lo offici divinal de la església. E feu molts altres libres de la santa scriptura los quals són fort autèntichs e approvats per santa mare església» (Wittlin 1995: 50). Es esta imagen, la de un san Jerónimo abad con hábito de religioso, ${ }^{47}$ la de un monje traductor, la de un asceta intelectual, la que quedó plasmada en la tabla de Gonçal Peris Sarrià destinada al monasterio de Portaceli, para presidir la capilla familiar de los Martí de Torres-Aguilar.

No estamos ante un caso excepcional. Por la misma época -hacia 1437- fra Filippo Lippi pintaba en Florencia al santo de modo muy parecido y con atuendo similar (fig. 2), y también lo hacía, en torno a 1444, Colantonio, uno de los máximos exponentes de la pintura napolitana del siglo XV, quien nos lo presenta en su estudio, rodeado de numerosos libros y papeles manuscritos sobre estantes, mesas y armarios, alusivos al trabajo de traductor del texto sagrado (fig. 3). Una actividad

pendiente de una revisión más profunda, la cual se realizará en estudios venideros», asegura Soler Fernández (2016/2017: 62).

46 En el retablo realizado hacia 1450 para la catedral de Segorbe por Jaume Mateu, Pilar Martino Alba (2001: 59 y 67) observa un san Jerónimo con ciertas similitudes. También encuentra coincidencias en algunas escenas, y señala que en los dos retablos aparecen «los remates en arcos polilobulados [...], pero con algunos de medio punto y otros carpaneles».

47 Mateu Rodrigo Lizondo, tras su lectura de este artículo, me traslada dos interesantes observaciones: que «el carácter fuerte» de san Jerónimo parece reflejado en la imagen, de gran fuerza expresiva; y que el color azul de su indumentaria, «permitido por la Iglesia para el hábito o ropa de uso de los clérigos», podría indicar la condición «de eclesiástico de rango» del cotitular del retablo. 
Agustín Rubio Vela. San Jerónimo en la onomástica de la familia Martí de Torres-Aguilar y su proyección en el retablo cuatrocentista de San Martín, del Museo de Bellas Artes de Valencia

subrayada repetidamente por el hagiógrafo: «Aquest és aquell lo qual translladà ab gran treball al poble crestià molts volums de libres -axí com la Bíblia e molts altres libres de la santa scriptura- de les lengües hebraica, caldea e grega en la nostra lengua latina». ${ }^{48}$

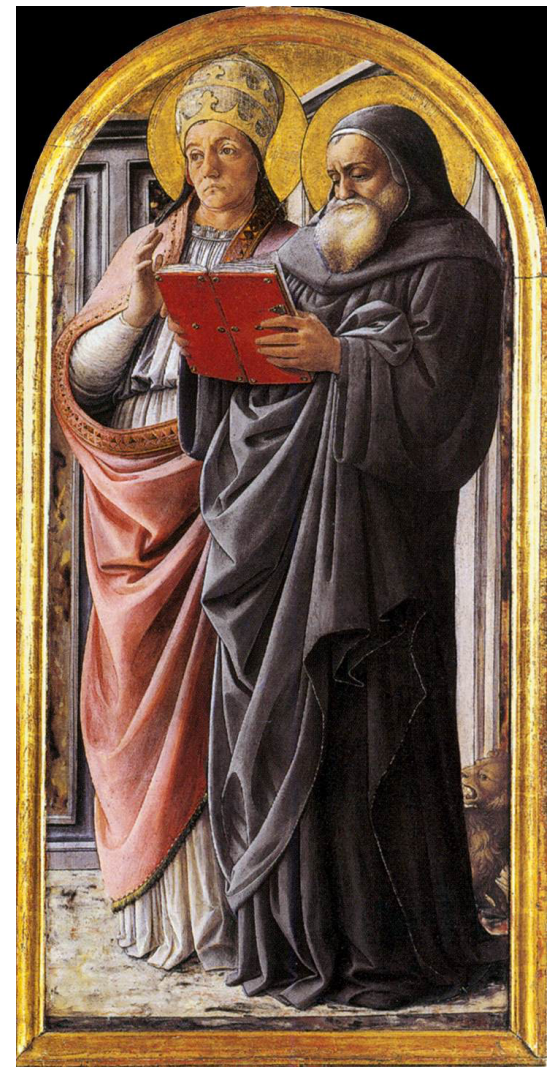

Fig. 2. Fra Filippo Lippi. San Gregorio y san Jerónimo (c. 1437).

Accademia Albertina di Belle Arti, Turín.

48 En líneas anteriores alude a sus tareas varias -«compilant, trelladant, esponent e declarant»-sobre el texto sagrado, «illuminant les penses o coratges dels hòmens, e esponent o declarant les figures o semblances de les santes scriptures e desnuant los nuus o laços d'aquelles, e declarant les coses escures hi esponent les coses dubtoses, e corregint les errors e falsedats, e compilant e ajustant e trahent de moltes lengües o lenguatges les veritats de les santes scriptures» (Wittlin 1995: 39-40).

SCRIPTA, Revista internacional de literatura i cultura medieval i moderna, núm. 16 / desembre 2020 / pp. 40-70 ISSN: 2340-4841 · doi:10.7203/SCRIPTA.16.19222 
Agustín Rubio Vela. San Jerónimo en la onomástica de la familia Martí de Torres-Aguilar y su proyección en el retablo cuatrocentista de San Martín, del Museo de Bellas Artes de Valencia

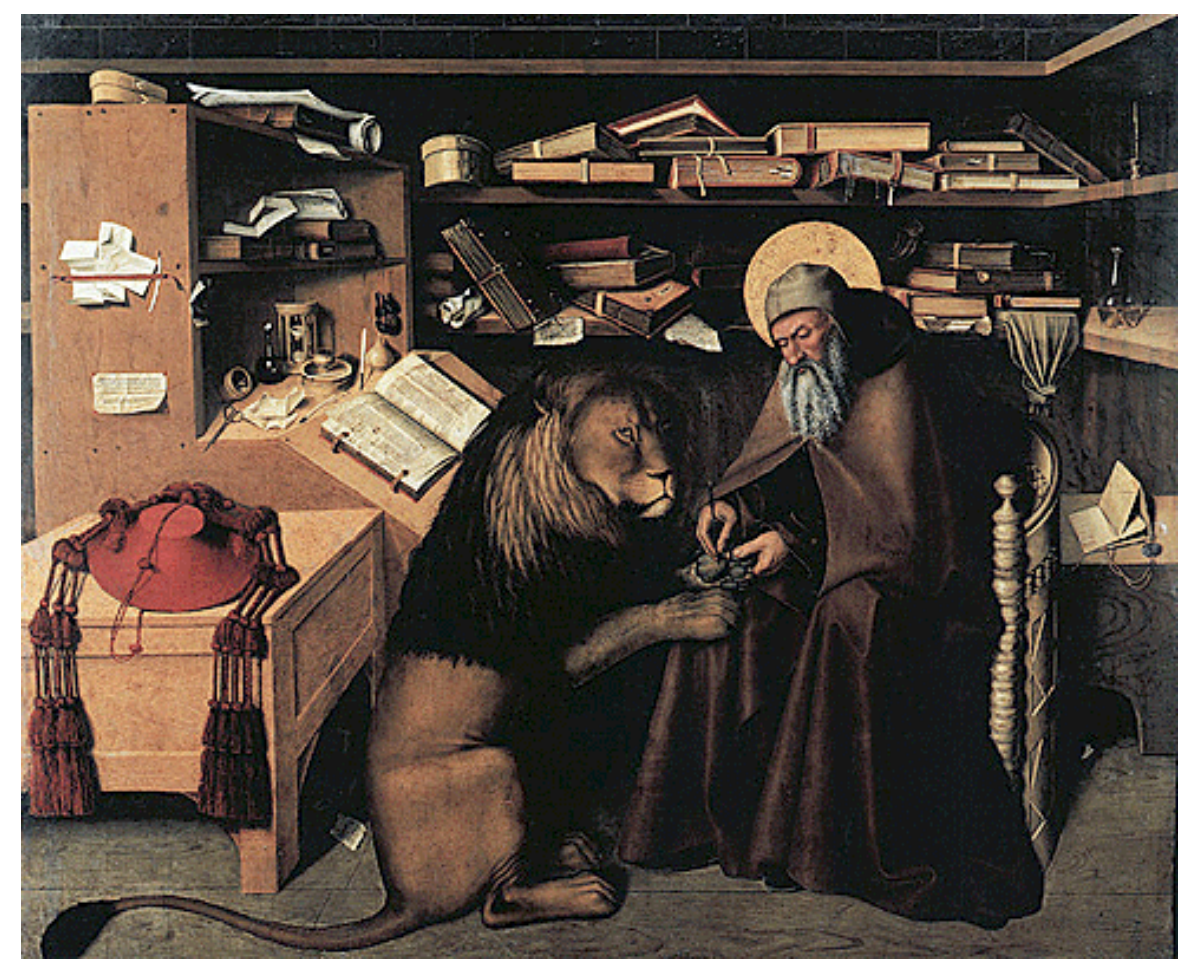

Fig. 3. Colantonio. San Jerónimo en su estudio (h. 1444).

Museo Nazionale di Capodimonte, Nápoles.

Hacia 1435, Masolino di Panicale lo pintó igualmente con hábito talar en uno de los frescos del baptisterio de Castiglione Olona, sentado en un pupitre sobre el que escribe y traduce. Al fondo, entre los códices, se percibe un pequeño rollo (fig. 4). No es irrelevante. Se trata de una referencia al quehacer específico del traductor, del hombre que tradujo al latín el texto hebreo del Antiguo Testamento, tarea para la que era preciso disponer de libros judíos, cuya forma era la del rollo. En este sentido fue mucho más explícito Ghirlandaio, quien en 1480, al representar al santo en su estudio -en este caso con el rojo cardenalicio- rodeado de utensilios heteróclitos, situó en los estantes del fondo, junto a dos códices, un par de rollos, uno de ellos cerrado y otro abriéndose, como si invitara al espectador a observar los caracteres hebraicos de su escritura, que contrastan con los latinos y los griegos, no menos ostensibles, de un libro y un papel próximos a él (fig. 5). 
Agustín Rubio Vela. San Jerónimo en la onomástica de la familia Martí de Torres-Aguilar y su proyección en el retablo cuatrocentista de San Martín, del Museo de Bellas Artes de Valencia

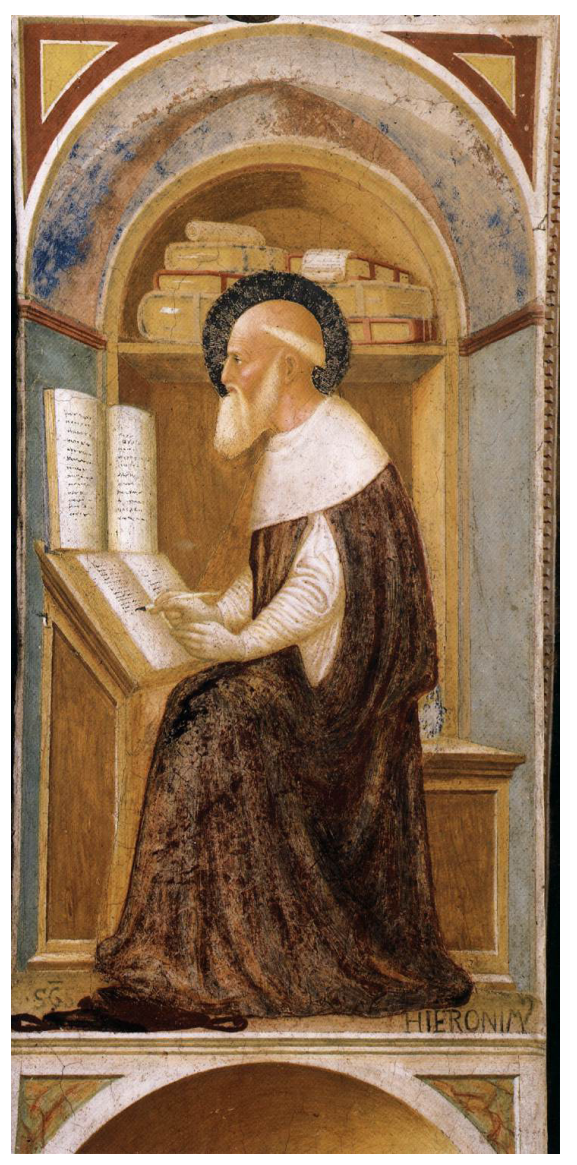

Fig. 4. Masolino di Panicale. San Jerónimo (1435).

Frescos del baptisterio de Castiglione Olona.

Un recurso igual emplearon el maestro Theoderic (fig. 6), Jaume Ferrer (fig. 7), Antonio da Fabriano (fig. 8) y Lorenzo Costa el Viejo (fig. 9), en cuyas obras, junto a los códices, aparece el rollo judaico en lugar visible, con función simbólica e identificadora. Se trataba así de evocar la gran obra de san Jerónimo, «la obra a la que dedicó gran parte de su existencia y por la que ha pasado a ocupar un lugar de honor en la Historia de la Iglesia: la exégesis bíblica y la traducción de los textos sagrados desde el hebreo y el griego al latín» (Martino Alba 2008: 272). 
Agustín Rubio Vela. San Jerónimo en la onomástica de la familia Martí de Torres-Aguilar y su proyección en el retablo cuatrocentista de San Martín, del Museo de Bellas Artes de Valencia
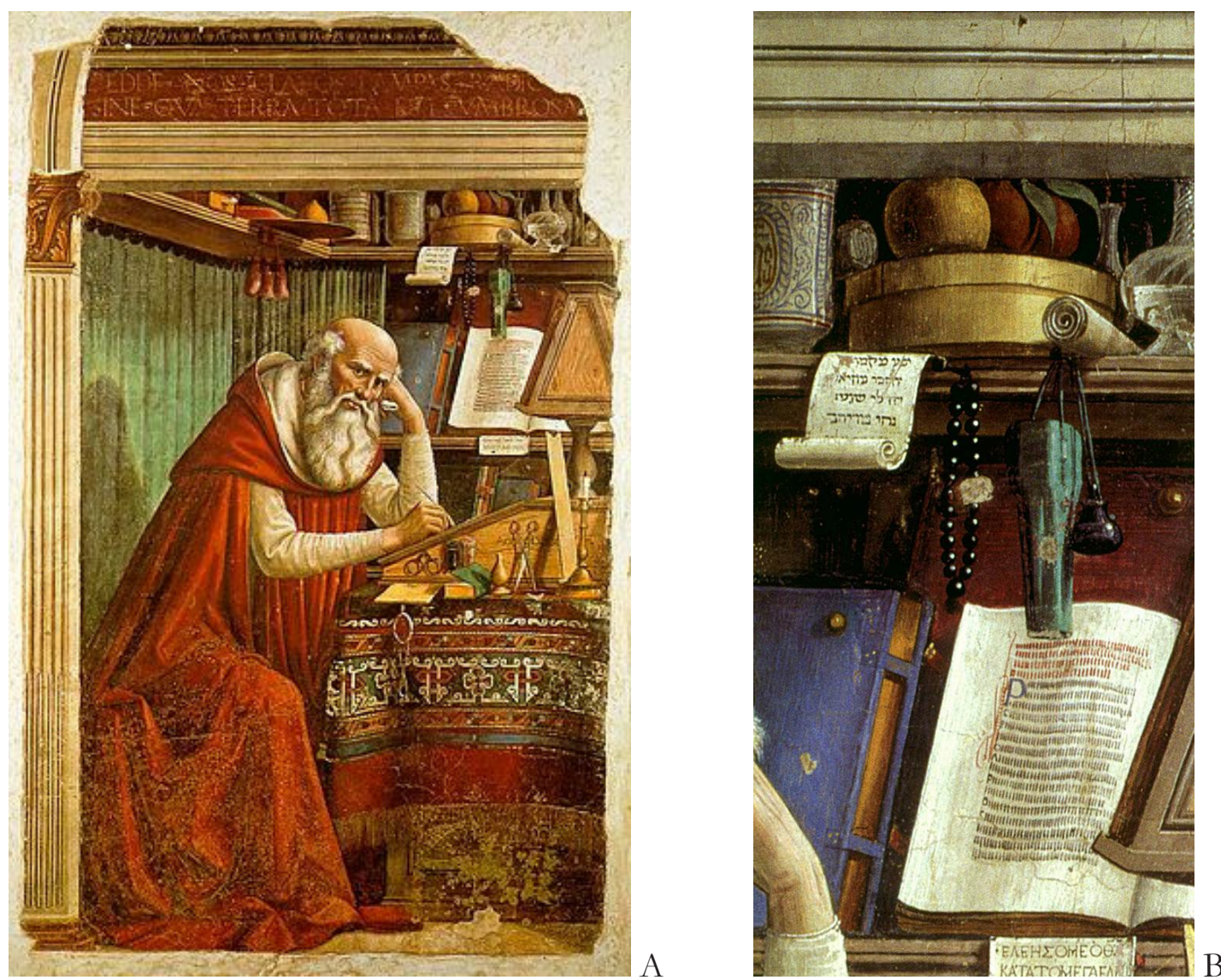

Fig. 5. Domenico Ghirlandaio.

A: San Jerónimo en su estudio (1480). Iglesia de Ognissanti, Florencia.

B: Detalle.

SCRIPTA, Revista internacional de literatura i cultura medieval i moderna, núm. 16 / desembre 2020 / pp. 40-70 ISSN: 2340-4841 · doi:10.7203/SCRIPTA.16.19222 
Agustín Rubio Vela. San Jerónimo en la onomástica de la familia Martí de Torres-Aguilar y su proyección en el retablo cuatrocentista de San Martín, del Museo de Bellas Artes de Valencia

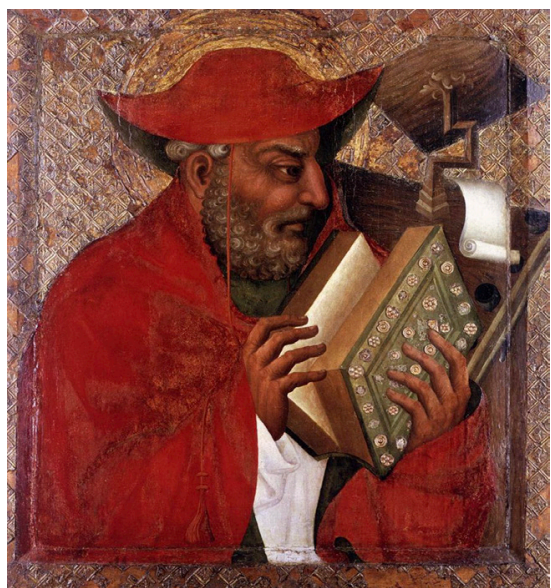

Fig. 6. Maestro Theoderic San Jerónimo (h. 1360-65). Národni Galerie, Praga.

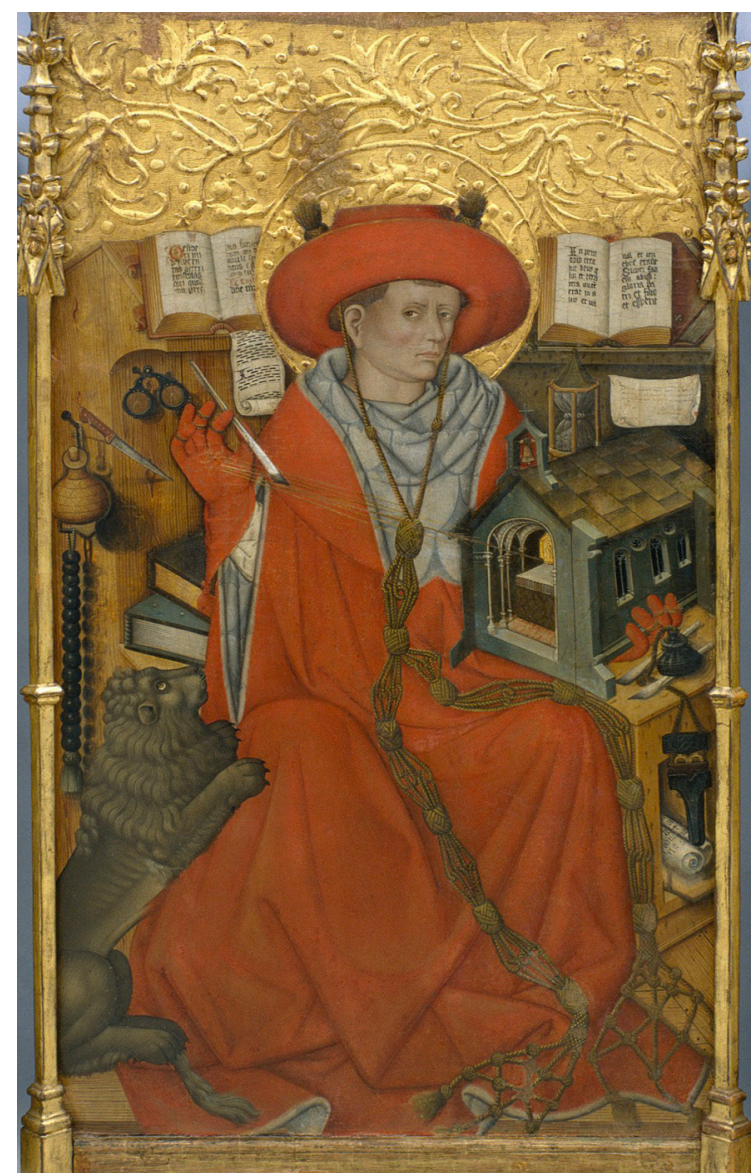

Fig. 7. Jaume Ferrer. San Jerónimo en su estudio (h. 1450). Museu Nacional d’Art de Catalunya, Barcelona.

SCRIPTA, Revista internacional de literatura i cultura medieval i moderna, núm. 16 / desembre 2020 / pp. 40-70 ISSN: 2340-4841 · doi:10.7203/SCRIPTA.16.19222 
Agustín Rubio Vela. San Jerónimo en la onomástica de la familia Martí de Torres-Aguilar y su proyección en el retablo cuatrocentista de San Martín, del Museo de Bellas Artes de Valencia

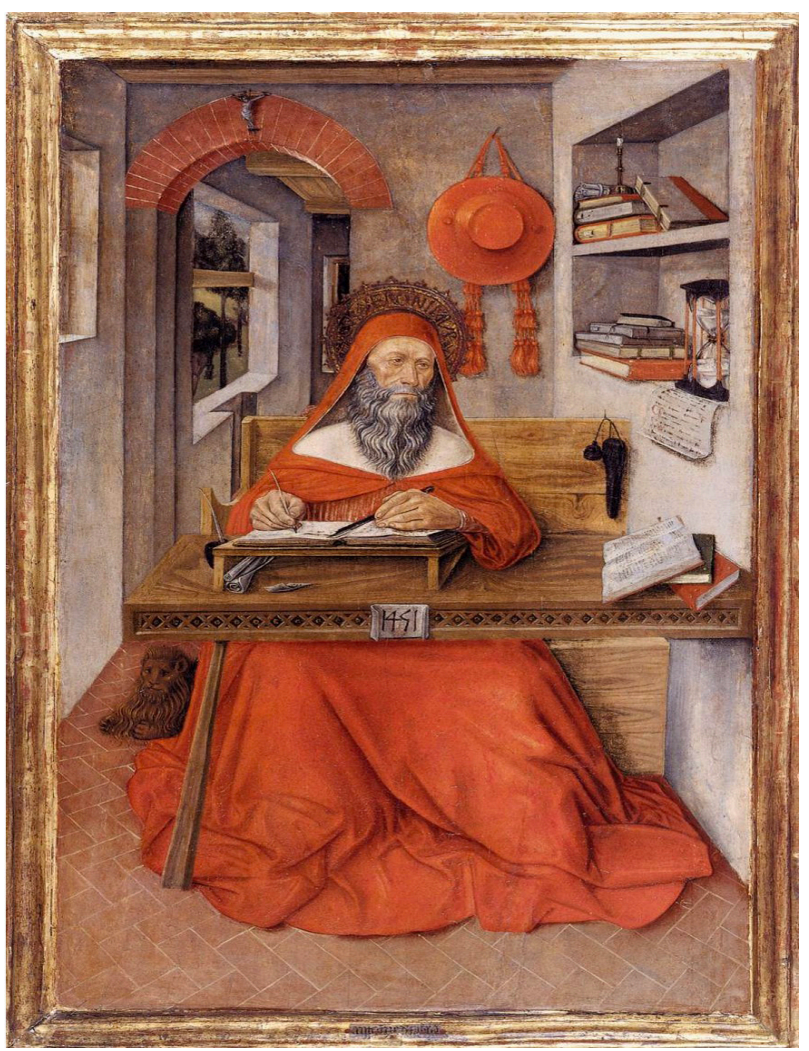

Fig. 8. Antonio Da Fabriano. San Jerónimo en su estudio (1451). The Walter Art Museum, Baltimore.

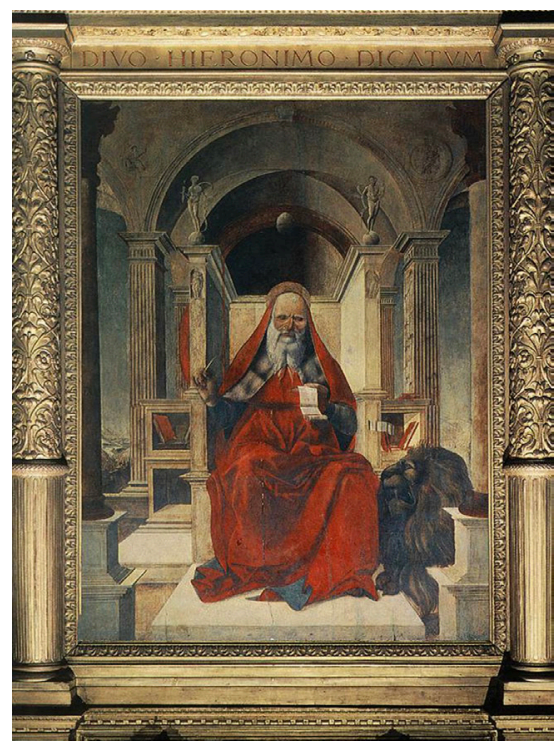

Fig. 9. Lorenzo Costa, el Viejo. San Jerónimo (1485). San Petronio, Bolonia.

SCRIPTA, Revista internacional de literatura i cultura medieval i moderna, núm. 16 / desembre 2020 / pp. 40-70 ISSN: 2340-4841 · doi:10.7203/SCRIPTA.16.19222 
Agustín Rubio Vela. San Jerónimo en la onomástica de la familia Martí de Torres-Aguilar y su proyección en el retablo cuatrocentista de San Martín, del Museo de Bellas Artes de Valencia

En el retablo valenciano, lo que en las representaciones cuatrocentistas solía ser un motivo disperso en el cuadro, un elemento figurativo alusivo al santo como traductor, se transforma en atributo identificativo y diferenciador. Un atributo doble y complementario, basado en el simbolismo del formato de los libros, del continente de éstos, distinto en los ámbitos judío y cristiano. Gonçal Peris Sarrià -o quien lo instruyese en la elaboración de la obra- parece haberse anticipado a lo que otros hicieron en centurias posteriores, cuando las imágenes muestran de manera realista e inequívoca que los dos atributos que presenta en sus manos san Jerónimo son la Vulgata y la Biblia de los judíos. Tal es el caso de la Madonna di San Girolamo, obra llevada a cabo por Correggio hacia 1528, donde se aprecian con total claridad los caracteres hebraicos del rollo que lleva el santo en su mano derecha, contrapunto del códice que exhibe en la izquierda (fig. 10).

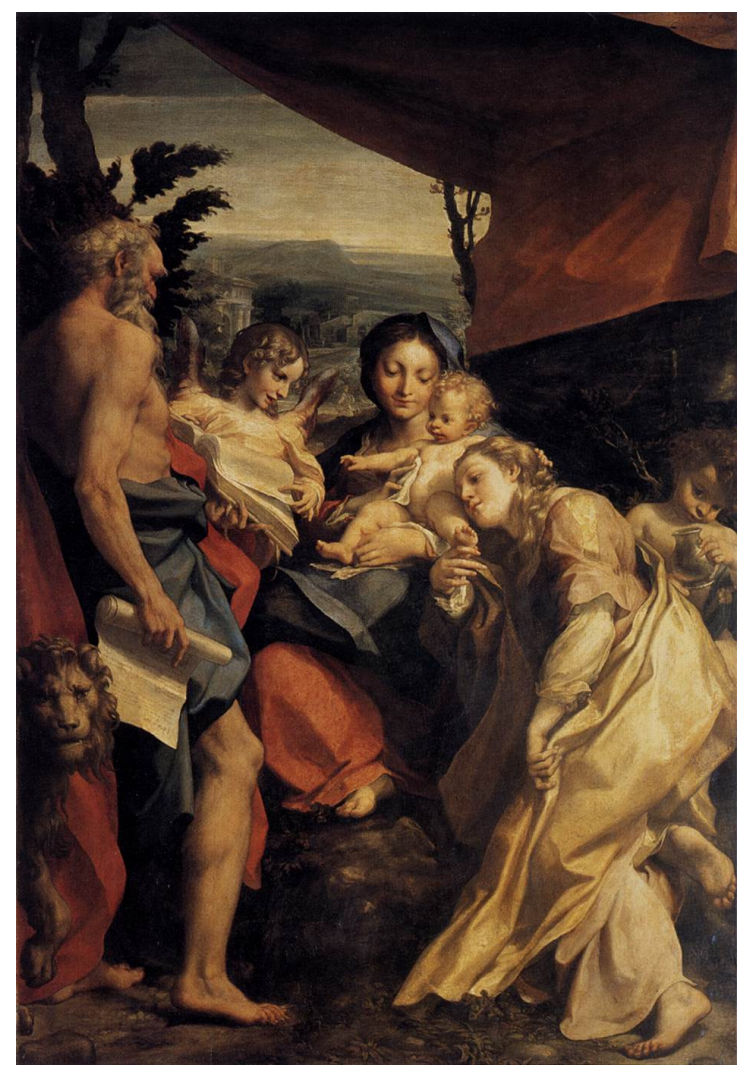

Fig. 10. Correggio. Madonna di San Girolamo (h. 1528). Galleria Nazionale, Parma. 
Agustín Rubio Vela. San Jerónimo en la onomástica de la familia Martí de Torres-Aguilar y su proyección en el retablo cuatrocentista de San Martín, del Museo de Bellas Artes de Valencia

En época barroca, cuando el espíritu contrarreformista dio impulso a la imagen de un san Jerónimo penitente y semidesnudo que realiza su labor traductora, prosiguió la fórmula. Efectivamente, con el rollo mosaico desplegado sobre el libro lo pintó Simon Vouet en su San Jerónimo y el ángel (fig. 11), y también José de Ribera en algunas de las numerosas obras sobre el santo que le fueron encargadas (Müller 1997: 92 y 95-96), entre las que cabe mencionar, por lo explícito de los caracteres hebraicos del texto bíblico que traduce sobre códice latino, el San Jerónimo penitente de la Real Academia de Bellas Artes de San Fernando de Madrid (fig. 12) y el San Jerónimo y el ángel del Hermitage (fig. 13).

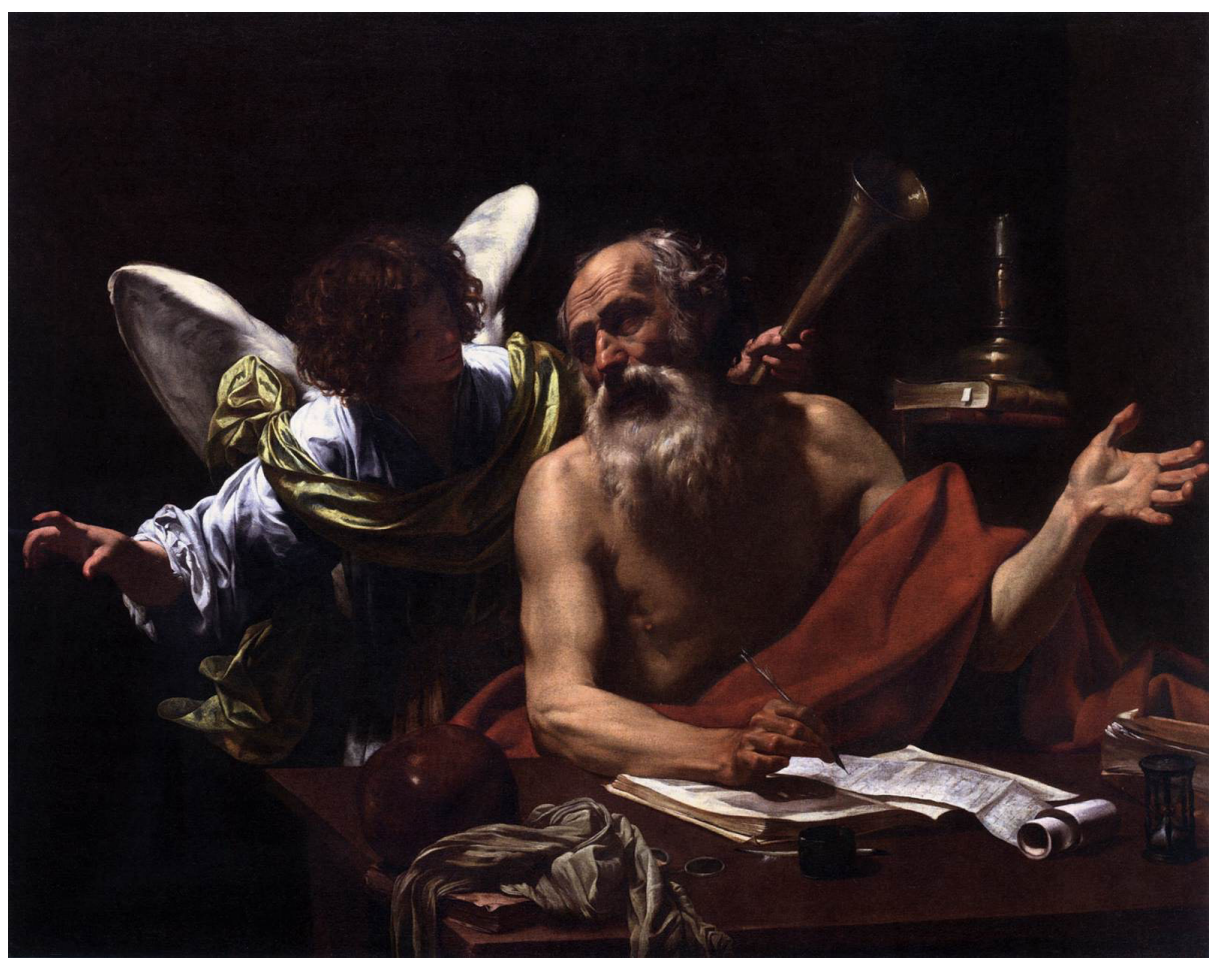

Fig. 11. Simon Vouet. San Jerónimo y el ángel (h. 1622-1625). National Gallery of Art, Washington D.C. 
Agustín Rubio Vela. San Jerónimo en la onomástica de la familia Martí de Torres-Aguilar y su proyección en el retablo cuatrocentista de San Martín, del Museo de Bellas Artes de Valencia

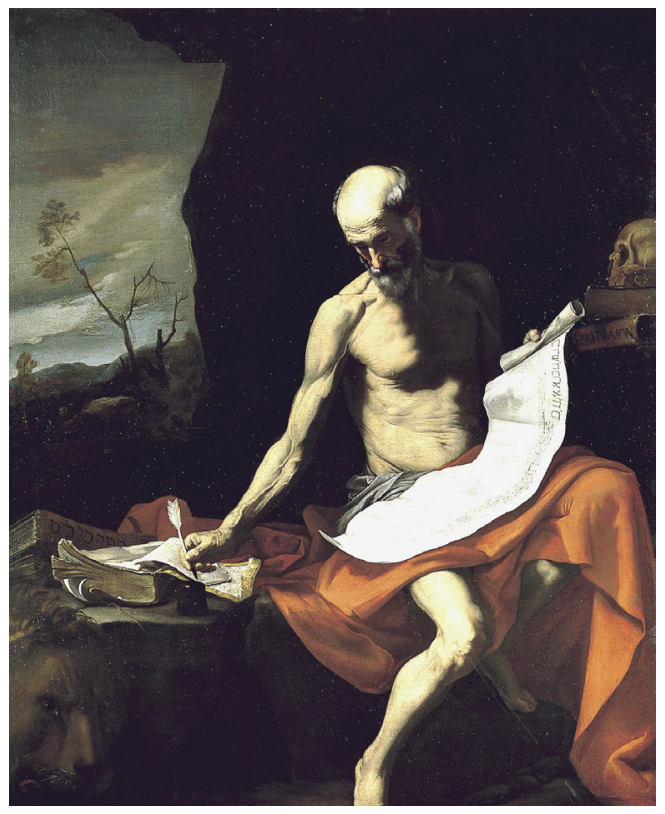

Fig. 12. José de Ribera. San Jerónimo penitente (h. 1645-1650). Real Academia de Bellas Artes de San Fernando, Madrid.

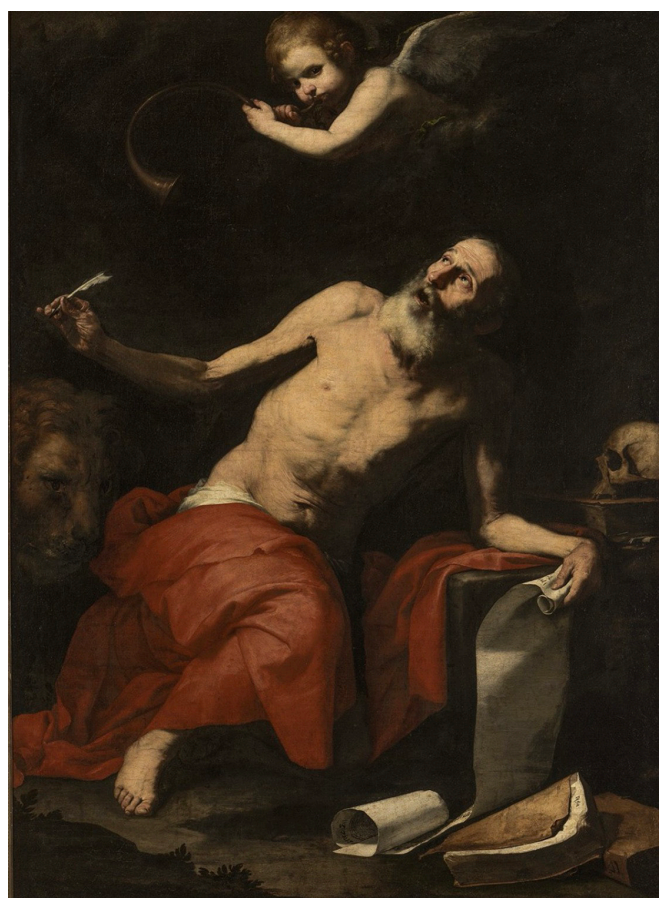

Fig. 13. José de Ribera. San Jerónimo y el ángel (h. 1626). State Hermitage Museum, San Petersburgo.

SCRIPTA, Revista internacional de literatura i cultura medieval i moderna, núm. 16 / desembre 2020 / pp. 40-70 ISSN: 2340-4841 · doi:10.7203/SCRIPTA.16.19222 
Agustín Rubio Vela. San Jerónimo en la onomástica de la familia Martí de Torres-Aguilar y su proyección en el retablo cuatrocentista de San Martín, del Museo de Bellas Artes de Valencia

\section{Conclusión}

Cobran sentido el libro y el rollo que porta en sus manos el abad anciano y barbado del retablo de San Martín. Cumplen una función identificadora clave que permite descartar la suposición de que el pintor representó a san Antonio, santo cuya imagen convencional -anciano, hábito de monje y un libro en las manos- es fácil de confundir con la de san Jerónimo, muy próximo a él, y no sólo en lo formal (Russo 1987: 234 y 245). Sorprendente es a veces el parecido entre ambos. El san Jerónimo -según nuestra hipótesis- de Gonçal Peris Sarrià y es muy similar al san Antonio abad pintado por Robert Campin, en la Virgen con el Niño y santos de la National Gallery de Washington (fig. 14). Pero, aunque en éste el flamenco cambió el códice por un pergamino enrollado -algo «totalmente inusual en la pintura gótica de la Corona de Aragón» (Gómez Frechina y Ruiz i Quesada 2014: 42)-, no cabe dudar de que representó a san Antonio: los otros atributos impiden confundirlo con cualquier santo de aspecto parecido.

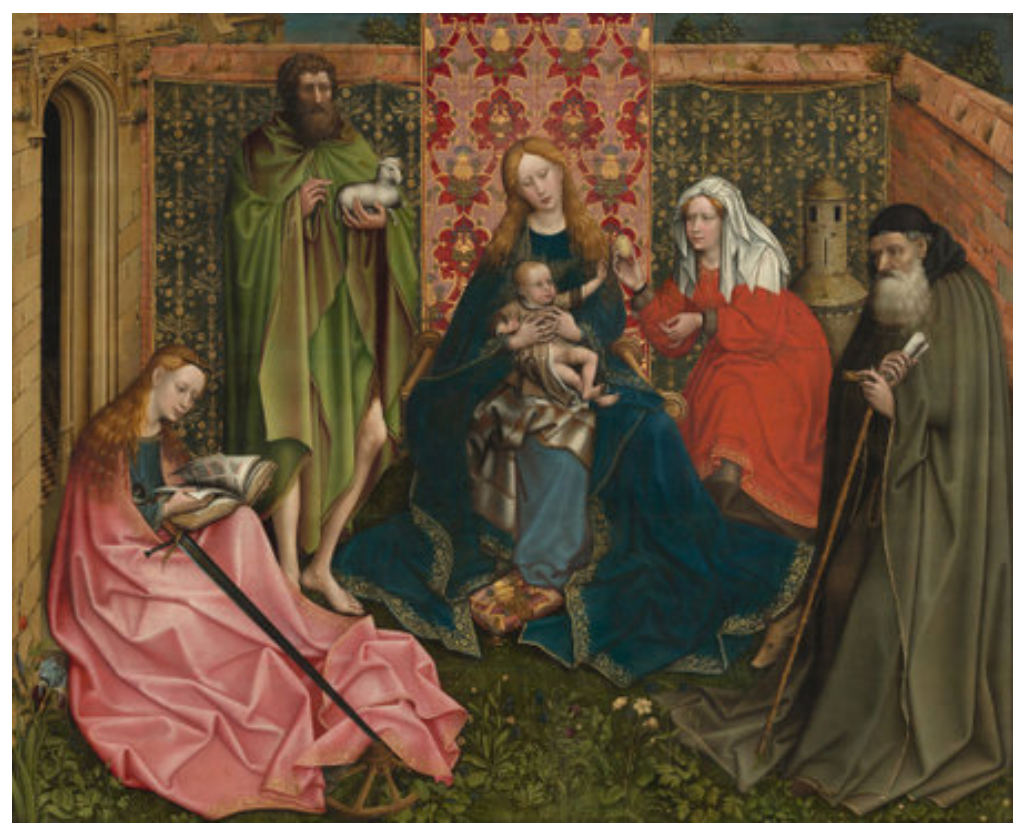

Fig. 14. Robert Campin. Virgen con el Niño y santos (h. 1425). National Gallery of Art, Washington.

En el retablo valenciano, el atributo diferenciador no es un libro -tampoco un rollo, como en el insólito caso anterior-, sino un libro y un rollo. Lo cual no encaja con la iconografía antoniana. Si del libro pudo suponer Saralegui (1954: 96) - «supongo alusivo», escribió- que tal vez fuesen las meditaciones eremíticas de san Antonio o las constituciones de la orden, del rollo confesó: «No 
Agustín Rubio Vela. San Jerónimo en la onomástica de la familia Martí de Torres-Aguilar y su proyección en el retablo cuatrocentista de San Martín, del Museo de Bellas Artes de Valencia

sé [...] a qué puede aludir el pergamino arrollado a su diestra, pensando si será (?) por referirse a sus Máximas». Por el contrario, el doble atributo sí encaja con la iconografía de san Jerónimo y se aviene a su imagen de traductor de la Biblia hebraica al latín. Él, el santo familiar de los Martí de Torres-Aguilar, hubo de ser el anciano abad que ellos quisieron que figurase en el retablo de su capilla en Portaceli. La onomástica, la iconografía y la hagiografía avalan esta interpretación.

Adra, 14 de noviembre de 2020

SCRIPTA, Revista internacional de literatura i cultura medieval i moderna, núm. 16 / desembre 2020 / pp. 40-70 ISSN: 2340-4841 · doi:10.7203/SCRIPTA.16.19222 
Agustín Rubio Vela. San Jerónimo en la onomástica de la familia Martí de Torres-Aguilar y su proyección en el retablo cuatrocentista de San Martín, del Museo de Bellas Artes de Valencia

\section{Apéndice documental}

Documento núm. 1.

1424, abril, 10.- Valencia.

El clavari de la ciudad de Valencia incluye entre los gastos municipales los tres florines pagados al notario Joan Martinez como salario por las escrituras de venta de un censo, por valor de 3.500 sueldos, a Úrsula, mujer en segundas nupcias de Berenguer Martí de Torres, como tutora de Jaume y Joana, hijos de su primer matrimonio con el jurista Jaume Garcia.

-AMV, Claveria Comuna O-8, f. 105r-v.

Item pos en data tres florins d'or, valents I lliura XIII sous reyals, los quals, de manament dels honorables, jurats doní e paguí a N Johan Martínez, notari scrivint en la scrivania de la Sala, precedent taxació a aquell feta per lo síndich, per son salari e treballs de recepció d'un carregament de CCL sous censals, fet per lo dit síndich per preu de $\mathrm{III}^{\mathrm{m}} \mathrm{D}$ sous, ab assentiment e voluntat dels dits honorables jurats, sobre la universitat de la dita ciutat, a la honorable dona $\mathrm{Na}$ Úrsula, muller que fon primera de l'honorable micer Jacme Garcia, licenciat en leys, e ara muller de l'honorable En Berenguer Martí de Torres, jurat de la dita ciutat l'any present, en nom e axí com a tudriu e curadriu de Jacme e Johana, donzella, fills e hereus del dit honorable quondam Jacme Garcia, e a ops d'aquells, per raó d'aquells $\mathrm{XV}^{\mathrm{m}}$ florins d'or, los quals, en virtut de dos consells celebrats en la dita ciutat, lo I a XVIII e l'altre a $\mathrm{XVIIII}^{\circ}$ de febrer proppassat, són estats offerts donar e liurar graciosament al molt alt senyor rey per les causes e rahons en aquells larch contengudes, segons del dit carregament appar per carta pública reebuda per lo dit notari a XXIIII de març proppassat de l'any dejús scrit, hon és clar veure. E ha-n’i albarà dels honorables jurats, scrit en València a X d'abril de l'any MCCCCXXIIII.

Documento núm. 2.

1455, diciembre, 5.- Valencia.

Úrsula Aguilar, mujer de Berenguer Martí de Torres, recibe del clavari de la ciudad de Valencia 5.600 sueldos, valor del censo comprado en 1402 por Joan Aguilar, que, tras haber sido beredado por su padre, el notario Joan Aguilar, sobrino del anterior, pasó a ser de ella en 1448, tras la muerte de Maciana, su madre.

-AMV, Quitament de censals, W-5, ff. 114r-115r.

Item paguí e doní a la honorable dona Na Úrsola, muller de l’honorable En Berenguer Martí de Torres, ciutadà de València, és saber, cinch mília siscents sous, per preu o quitament de aquells trescents setanta tres sous quatre diners de la dita moneda censals, los quals en dies passats per los honorables tunch jurats e síndich de la dita ciutat foren venuts e originalment carregats sobre los béns e drets de la dita universitat a l'honorable En Johan Aguilar, laurador, ciutadà de la dita ciutat, 
Agustín Rubio Vela. San Jerónimo en la onomástica de la familia Martí de Torres-Aguilar y su proyección en el retablo cuatrocentista de San Martín, del Museo de Bellas Artes de Valencia

e als seus, pagadors cascun any a huyt de març en una paga, ab carta pública de venda e carregament feta en València a set de març de l'any de la nativitat de nostre senyor Déu mil CCCC dos, rebuda per lo honrat e discret En Berthomeu Cerdà, notari e lavors scrivà dels honorables jurats e consell de la dita ciutat. Enaprés lo dit En Johan d'Aguilar, comprador del dit censal, morí, e ab son derrer testament, fet en València a dos de deembre de l'any MCCCC quatre, clos e sots signat de la mà del discret En Berthomeu Martí, notari, instituhí a sí hereu universal lo honorable En Johan Aguilar, notari, ciutadà de la dita ciutat, nebot seu e pare de la dita $\mathrm{Na}$ Úrsola. E jatsia per virtut de una sentència donada per lo noble N'Arnau Guillem de Bellera, lavors visrey e governador del regne de València, lo sobredit censal, axí com a béns del pare de la sobredita $\mathrm{Na}$ Úrsola, fon confiscat al senyor rey e fon totalment per la dita ciutat remut, e per consegüent extinch, emperò, les dites coses no obstants, per consell general en la Sala de la ciutat en la forma acostumada celebrat a quatre del mes de març del propdit any fon provehit les pensions del dit censal esser pagades al dit honrat En Johan Aguilar, pare de la dita Na Úrsola, segons en aquell al qual me reffer és larch contengut. E encara, jatsia sobre les dites coses ara en lo temps del quitament del dit censal fossen fets alguns duptes, non sens rahó, emperò, per los honorables jurats, de consell de l'honorable micer Johan de Gallach, doctor en leys, hu dels honorables advocats de la dita ciutat, fon expresament concordat que, no obstant les dites coses, fos per mi rebut lo dit quitament e fos per mi, dit clavari, pagat lo preu e pensions del dit censal a la dita honrada $\mathrm{Na}$ Úrsola segons en la dita provisió, la qual és continuada en actes de consells a tres del present mes de deembre, les dites coses és clar veure. Enaprés, lo pare de la dita Na Úrsola morí e ab son derrer testament, fet en València a XI de deembre de l'any de la nativitat de nostre senyor MCCCCXXXVII e publicat a sis del dit mes en poder de l'honrat e discret En Francesch Pérez, notari, instituhí hereva sua universal la honrada dona Na Maciana, muller del dit En Johan Aguilar e mare de la dita Na Úrsola. E jatsia la dita Na Maciana hagués fet donació a la dita $\mathrm{Na}$ Úrsola del sobredit censal, emperò, ella, aprés, de voluntat de la dita Na Úrsola, fon revocada la dita donació. Segons consta ab son derrer testament, fet en València a tres del mes de noembre de l'any de la nativitat de nostre Senyor mil CCCCXXXX e publicat a XX de noembre de l'any mil CCCCXXXXVII per lo dit En Francesch Pérez, notari, instituhí hereves sues universals a la sobredita $\mathrm{Na}$ Úrsola e la honrada dona $\mathrm{Na}$ Ysabel, germana sua, filles del dit En Johan Aguilar, les quals vengueren a partició e divisió de tots los béns de la dita herència, e pervengué lo sobredit censal a la part de la dita $\mathrm{Na}$ Úrsola, segons consta ab carta pública de divisió rebuda per lo sobredit En Francesch Pérez, notari, a XX de janer de l'any MCCCCXXXXVIII. E d'altra part li paguí e doní cent setanta set sous, sis diners de la dita moneda per pensió prorata dels dits CCCLXXIII sous, IIII diners de la dita moneda, censals, rendals, annuals, comprada, de cinch meses vint dos dies, finits lo primer dia de setembre proppassat, en lo qual dia fon intimat lo dit quitament; e ha-n'i carta de quitament, rebuda per lo honrat e discret En Jacme Beneyto, notari, scrivà dels honorables jurats e consell de la ciutat de València, feta a V de deembre de l'any MCCCCL cinch; les quals dos partides, reduhides a compte de lliures, munten e prenen suma de CC huitanta huyt lliures, desset sous, sis diners de la sobredita moneda: CCLXXXVIII lliures, XVII sous, VI.

SCRIPTA, Revista internacional de literatura i cultura medieval i moderna, núm. 16 / desembre 2020 / pp. 40-70 ISSN: 2340-4841 · doi:10.7203/SCRIPTA.16.19222 
Agustín Rubio Vela. San Jerónimo en la onomástica de la familia Martí de Torres-Aguilar y su proyección en el retablo cuatrocentista de San Martín, del Museo de Bellas Artes de Valencia

\section{Bibliografía}

Aliaga Morell, J. (2016) «Gonçal Peris y Gonçal Peris Sarrià, dos pintores contemporáneos del gótico internacional valenciano», Ars Longa, 25, pp. 35-53.

Campón Gozalvo, J. (1991) Historia de Nuestra Señora de la Murta, Alzira, Ayuntamiento de Alzira.

Delicado Martínez, F. J. (1999) «Los monasterios jerónimos valencianos: su diversa suerte tras la desamortización de Mendizábal y la dispersión de su legado cultural», en La Orden de san Jerónimo y sus Monasterios, San Lorenzo del Escorial, II, pp. 785-806.

Delicado Martínez, F. J., \& Ballester Hermán, C. (2000) «El monasterio de Cotalba (Gandía), una fundación jerónima del siglo XIV», Ars Longa, 9-10, pp. 73-86.

Ferre Puerto, J. (1999) «Trajectòria vital de Joan Reixac, pintor valencià del quatre-cents: la seua relació amb Andreu Garcia», L'artista-artesà medieval a la Corona d'Aragó, Lleida, pp. 419-425.

Gómez-Ferrer, M. (2010): «Nuevas noticias sobre retablos del pintor joan Reixach (act. 14371486)», Archivo de Arte Valenciano, XCI, pp. 39-52.

Gómez Frechina, J. (2004) «Gonçal Peris y el retablo de San Martín, Santa Úrsula y San Antonio abad», en Obras maestras restauradas. El retablo de San Martín, Santa Úrsula y San Antonio abad, Museo de Bellas Artes de Valencia, Madrid, BBVA, pp. 84-122.

Gómez Frechina, J., \& Ruiz i Quesada, F. (2014) «En torno al retablo de San Martín de Portaceli y sus autores: El Maestro de Martí de Torres y Gonçal Peris Sarrià), Retrotabulum. Estudis d'art medieval, 14, pp. 2-58.

Graullera Sanz, V. (1998) «Un jurista valenciano del siglo XV, don Jaime García Aguilar», Quaderns d'investigació d'Alaquàs, 17, pp. 9-22.

- - (2007) «La biblioteca de don Jaime García de Aguilar. La trayectoria intelectual de un jurista valenciano en el siglo XV», Quaderns d'investigació d'Alaquàs, 27 (2007) 11-28.

- (2009) Derecho y juristas valencianos en el siglo XV, Valencia, Generalitat Valenciana.

Gustà, M.(ed.) (1980) Joan Roís de Corella: Tragèdia de Caldesa i altres proses, Barcelona, Edicions 62.

Hernàndez García, A. (2012) «La familia Martí de Torres y el señorío de Alaquàs», Quaderns d'investigació d'Alaquàs, 32, pp. 11-64.

——. (2015) «El señorío de Alaquàs y los linajes Martí de Torres, García de Aguilar y Pardo de la Casta (siglos XV-XVIII)», Quaderns d'investigació d'Alaquàs, 35, pp. 11-64.

López-Yarto, A. \& Mateo Gómez, I., \& Ruiz Hernando, J. A. (1995) «El monasterio jerónimo de Santa María de la Murta (Valencia)», Ars Longa, 6, pp. 17-23.

Juan Redal, E. (1988) «Dades per a l'estudi de la societat valenciana del segle XVI: els últims codicils testamentaris i l'inventari de béns d'en Jaume Garcia d'Aguilar, senyor d'Alaquàs», Quaderns d'investigació d'Alaquàs, 7, pp. 9-50.

SCRIPTA, Revista internacional de literatura i cultura medieval i moderna, núm. 16 / desembre 2020 / pp. 40-70 ISSN: 2340-4841 · doi:10.7203/SCRIPTA.16.19222 
Agustín Rubio Vela. San Jerónimo en la onomástica de la familia Martí de Torres-Aguilar y su proyección en el retablo cuatrocentista de San Martín, del Museo de Bellas Artes de Valencia

Martino Alba, P. (2001) «El retablo de san Jerónimo, de Jaume Mateu en la catedral de Segorbe (Castellón)», Cuadernos de arte e iconografía, 10, pp. 59-74.

- (2008) «San Jerónimo viajero: iconografía de un peregrinaje vital», en El culto a los santos. Cofradías, devoción, fiestas y arte, San Lorenzo del Escorial, Ediciones Escurialenses, pp. 271-284.

Montero Tortajada, E. (2013) «El oligarca y los pinceles: breve semblanza del presbítero Andreu Garcia», Espacio, tiempo y forma, 1, pp. 401-418.

Müller, K. (1997) «La imagen de san Jerónimo en la obra de Ribera», Norba-Arte, XVII, pp. 89-98.

Navarro Espinach, G. \& Martínez Vinat, J. (2016) La Cofradía de San Jerónimo del «Art de Velluters» de Valencia. Fundación y primeros años (1477-1524), Valencia, Generalitat Valenciana.

Ollaquindia Aguirre, R. (2004) «Noticias sobre la Tau y los antonianos», Cuadernos de etnología y etnografía de Navarra, 79 , pp. 157-173

Palomar Macián, V., \& Lozano Pérez, L. (2017) «Una fundación de la orden jerónima en Segorbe: el monasterio de Ntra. Sra. de la Esperanza», La Linde, 8, pp. 300-326.

Rubio Vela, A. (2000) Alfons de Borja y la ciudad de Valencia (1419-1458). Colección de documentos del Archivo Histórico Municipal, Valencia, Fundación Valencia Tercer Milenio.

- (2012) El patriciat i la nació. Sobre el particularisme dels valencians en els segles XIV i XV, CastellóBarcelona, Fundació Germà Colón Domènech, 2 vol.

—. (2013) «El context històric de Joan Roís de Corella. Tríptic documental sobre el seu entorn», Afers, 76, pp. 593-615.

—. (2014) «Joan Roís de Corella, el mundo de los caballeros y la guerra. Notas de archivo sobre notas de lectura», eHumanista/IVITRA 5, pp. 443-466.

- (2017) Joan Aguilar, escrivà de la Sala de la ciudad de Valencia (1423-1425). Voluntad de estilo en las misivas municipales, Valencia, Gráficas Papallona.

- (2016) Valencia, el príncipe de Viana y Juan II. Un patriciado ante la crisis política de la monarquía (1460-1461), Valencia, Gráficas Papallona.

- (2020) Los Castellvi en la Baja Edad Media valenciana. Generacionesy semblanzas de un linaje, Valencia, Gráficas Papallona.

Rubio Vela, A. \& Rodrigo Lizondo, M. (1984) «Els beguins de València. La seua casa-hospital i els seus llibres», en Quaderns de Filologia. Estudis en memòria del professor Manuel Sanchis Guarner, I, pp. 327-341. Hay segunda edición: Ferrando, A., (ed.) (1992) Miscel lània Sanchis Guarner, III, pp. 185-227.

Rubio Vela, A., \& Rodrigo Lizondo, M. (1997) Antroponimia valenciana del segle XIV. Nòmines de la ciutat de València (1368-69 i 1373), València/Barcelona, Institut Interuniversitari de Filologia Valenciana.

SCRIPTA, Revista internacional de literatura i cultura medieval i moderna, núm. 16 / desembre 2020 / pp. 40-70 ISSN: 2340-4841 · doi:10.7203/SCRIPTA.16.19222 
Agustín Rubio Vela. San Jerónimo en la onomástica de la familia Martí de Torres-Aguilar y su proyección en el retablo cuatrocentista de San Martín, del Museo de Bellas Artes de Valencia

Russo, D. (1987) Saint Jérôme en Italie. Étude d'iconographie et de spiritualité (XIII -XV siècle), París-Roma, École Francaise de Rome.

Saralegui, L. de (1954) El Museo Provincial de Bellas Artes de San Carlos: Tablas de las salas $1^{a}$ y $2^{a}$ de primitivos valencianos, Valencia, Institución Alfonso el Magnánimo.

Soler Fernández, J. (2016/2017) La heráldica y los retratos en los retablos y tablas valencianas de los siglos XV e inicios del XVI, Trabajo de Master dirigido por Mercedes Gómez-Ferrer Lozano, Universitat de València.

Tarín Juaneda, F. (1897) La Cartuja de Porta-Coeli (Valencia). Apuntes históricos, Valencia, Establecimiento tipográfico de Manuel Alufre.

Teixidor, J. (1895) Antigüedades de Valencia, ed. R. Chabàs, València, F. Vives Mora, 2 vol.

Valldecabres Rodrigo, R. (2002) El cens de 1510. Relació dels focs valencians ordenada per les corts de Montsó, Valencia, PUV.

Vicens Vives, J. (2006) Historia crítica de la vida y reinado de Fernando II de Aragón, ed. M. A. Marín Gelabert, Zaragoza, Institución "Fernando el Católico".

Wittlin, C. (ed.) (1995) Eusebi-Agusti-Ciril (autors ficticis). Tres epistoles sobre la vida $i$ trànsit del gloriós sant Jeroni, Barcelona, Curial Ediciones Catalanes.

SCRIPTA, Revista internacional de literatura i cultura medieval i moderna, núm. 16 / desembre 2020 / pp. 40-70 